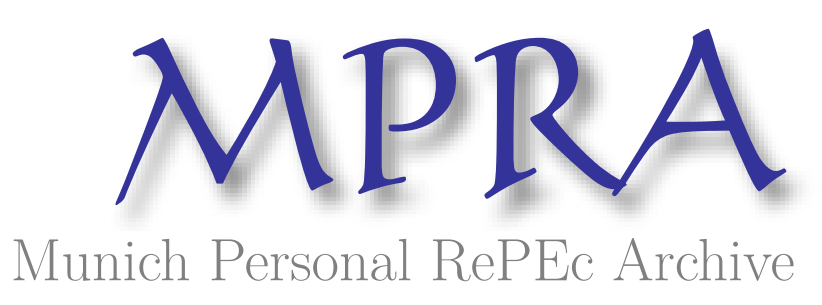

\title{
Safety and the Allocation of Costs in Large Accidents
}

Langlais, Eric

30 September 2010

Online at https://mpra.ub.uni-muenchen.de/25710/

MPRA Paper No. 25710, posted 09 Oct 2010 19:13 UTC 


\title{
Safety and the Allocation of Costs in Large Accidents
}

\author{
Eric LANGLAIS*
}

September 2010

\section{Introduction}

This paper focuses on the unilateral accident model in an economy having three main features: 1/ individuals (both injurers and victims) are Rank Dependant Expected Utility maximizers, which allows us to capture two important behavioral characteristics in risk, both pessimism (probability transformation) and risk aversion, which are mainly documented in experimental works; $2 /$ there exists an aggregate risk in case of accident which entails monetary losses which are not perfectly compensable, which seems to fit well with the occurrence of accidents leading to large/catastrophic losses; 3/ finally, tortfeasors have the opportunity to invest in damages reduction activities having a monetary cost of effort (hence assuming the perfect susbstitutability between the cost of effort and wealth) which is a good approximation of the cases where the available technology enables to monitor more precisely the consequences of the accident (losses) than the likelihood of the accident. Thus, our framework departs from previous literature, which considers economies with pure individual risks and perfectly compensable losses (Arlen (1992), Miceli and Segerson (1995), Shavell (1982)) and/or contexts in which care reduces the probability of accidents (Nell and Richter (2003), Graff Zivin, Just and Zilberman (2006)). As in our companion paper (Dari-Mattiacci and Langlais (2009)) we add to the literature on questions still in debate: efficient risk sharing rules with endogenous transaction costs (Borch (1962), Raviv (1978)); the relationship between safety standards and wealth (Arlen (1992), Miceli and Segerson (1995), Shavell (1982)); the separation between incentives to prevention, risk sharing and redistributive

*EconomiX-CNRS \& Paris Ouest Nanterre, and LEF-INRA-AgroParisTech Nancy; Eric.Langlais@nancy-engref.inra.fr. I thank the participants to the 59th AFSE Annual Conference, Paris 9-10 September 2010, and to the 27th EALE Annual Conference, Paris 23-25 September 2010. The financial support provided by the MEEDDM (RDT program 2006) is gratefully acknowledged. This work is also part of a research programm developped at Laboratoire d'Economie Forestière (UMR 356 INRA-AgroParisTech) in Nancy, during my term as a visiting-professor. 
objectives (Shavell $(1981,1982)$, Kaplow and Shavell $(1994,2000)$ ); the equivalence between, and efficiency of, basic liability rules (Brown (1973), Landes and Posner (1987), Shavell (1987)).

We characterize the first best of this economy, both in terms of safety expenditures and risk sharing. Specifically, we show that the first best level of care is higher than in a risk-neutral economy, reflecting the existence of an aggregate (non diversifiable) risk which has to be redistributed among society (and thus, shared between injurers and victims) - hence, the first best allocation of risk is such that it is generally not efficient that one party obtains full coverage against the aggregate risk. Moreover, it appears that socially efficient expenditures in safety depend on the aggregate wealth of the economy, which is in contrast with canonical results obtained in the risk neutral/perfectly insurable risk case (Miceli and Segerson (1995), Shavell (1982)) - however the specific sign of this relationship is shown to be ambiguous. We also show that society's pessimism has an ambiguous effect on care expenditures; the exception is when society's preferences are immune against variations of wealth (i.e. under constant marginal utility), since more pessimism always yields higher safety expenditures.

Turning to the functioning of tort law and basic liability rules, we find that both strict liability and negligence are no more equivalent under risk aversion, although they generally both fail in implementing the first best. The reason is that reaching the first best requires enough instruments in order to transfer wealth in each states, and to set the care level to the due standard; in contrast, a liability rule is associated at best to a due care and to a transfer in the unique event that the accident occurs. As a result, strict liability (but only with compensatory damages) implements only a second best care level in the specific sense defined thereafter (when the < moral constraint 〉> is taken into account according to which innocent victims must be fully compensated for the injuries they suffer) - and this one may be higher than the first best. Negligence may fail to induce compliance when the due care is set to its first best level; it may also fail to reach the second best level, excepted when full compensatory damages are considered. The reason is that both the first best and the second best care level may represent high safety expenditures, such that the tortfeasors may have no incentives to adhere such a high standard given the distortion in risk allocation implied by the negligence rule.

The paper has also a close look at the issue regarding the preferences of the agents, comparing the standard Expected Utility model and the Rank Dependant Utility model. In particular, we show the conditions under which a RDEU economy has care expenditures higher than a EU economy. We also give weak conditions regarding the priors and beliefs on the states of the natures, under which for any EU economy there always exists a RDEU economy having the same first best level of safety activity and the same risk sharing rules. This suggests in contrast to Bigus (2006), Eide (2005) and Teitelbaum (2006) that the way the state independent risk aversion assumption is modeled may not matter so much. Also in contrast to these works, our paper insists that the main issue is the existence of an aggregate risk, since it implies that the choice of the care level is no more independent of the risk sharing arrangements. However, we 
show that in contrast to a EU economy, the degree of pessimism characterizing RDEU risk averse individuals affects both the level and sensibility of the efficient care: pessimism tends to boost safety activities over the risk neutral level, but may render them less sensible to the probability of accident - such results also contrast with those of Bigus (2006), Eide (2005) and Teitelbaum (2006). As a result pessimism disturbs both the functioning of strict liability and negligence, whether insurance liability is available or not. To illustrate with a simple but significant example, we show that even when injurers obtain full insurance for liability, this not lead them to undertake neither the first best care level, nor the risk neutral one.

In section 2, we discuss more extensively the motivations of the paper, in the light of the standard analysis of tort laws, and also with reference to more recent papers which deal with the issue of society's non neutrality to risk. In section 3, we present our framework, and characterize the properties of the first best for a RDEU economy when an aggregate risk exists. Section 4 discusses the functioning of liability rules, with and without the existence of insurance liability. Section 5 concludes.

\section{Motivations and backgrounds}

The widely used model in the literature on Tort Law (see Shavell (1987), Deffains and Langlais (2009) for a survey) is a very stylized situation of a unilateral accident: one party (one or several victims) is injured by an accident due to the wrongdoing of a second party (an injurer). The hazard which leads to the accidental event hurting the victim(s) is an avoidable by-product of the main productive activity of the injurer, this last one being socially useful. The injurer has the opportunity to invest in a safety technology (he may undertake precautions, or care) to reduce the level of expected damage when the accident occurs. Both individuals are supposed to be risk-neutral: this basic framework will be labelled a risk-neutral world. In this case, any feasible allocation of risk (any allocation of the aggregate wealth) is Pareto efficient, and the first-best level of care satisfies (see Calabresi (1970), Diamond (1974a,b), Green (1976)):

$$
-p h^{\prime}(\hat{x})=1
$$

meaning that the risk-neutral or risk-free level of care $\hat{x}$ is set such that the planner weighs the victim's expected benefit resulting from the loss reduction (LHS of the equality) and the marginal cost of care borne by the injurer (RHS). Remark that Shavell (1982) obtains the same result for the level of care but in an economy with purely idiosyncratic risks: when there is no aggregate risk to be shared (i.e. soon as the expected aggregate wealth is constant across the sates of the world), the issue of the efficient level of safety becomes independent from the issue of the allocation of risks. It is easy to verify that $\hat{x}$ increases in $p$ but depends neither on society's aggregate wealth, nor on the distribution of such wealth among individuals - it only depends on the characteristics of the technology of prevention available to this economy. 
In other words, this framework fits well situations where specific institutions specialized in the management of risks are available, while safety activity is decentralized to private entities; then a complete separation is obtained between the allocation of risks in the society (among private entities or individuals), the compensation of losses to the victims of accident, and the design of incentives to invest in safety. This requires that small, individual, risks only exist in the economy. But, most accidents regarding industrial plants (chemical, nuclear and so on ...) are large ones, in the sense that they injure a great number of victims at the same time, leading to the existence of catastrophic losses ${ }^{1}$. In such contexts, strict liability is widely seen as the most suitable way to govern highly risky activities (environmentally or healthy dangerous production). The argument is that strict liability is supposed to induce both efficient care and an efficient level of the risky activity itself, whereas negligence will lead to a higher (inefficient) level of output.

Nell and Richter (2003) consider a world of Expected Utility parties having constant absolute risk aversion. They show that, if insurance markets are imperfect, the negligence rule implies a result in terms of risk sharing that should be preferred. The reason is that highly risky activities typically affect a large number of individuals, such that strict liability implies a quite unfavorable allocation of risk. Therefore, the negligence rule turns out to be superior, if a market relationship between the parties exists, since it incurs less cost of risk. If there is no market relationship between injurer and victims, no clear result can be derived.

Graff Zivin and ali (2006) investigates the performance of liability rules in a sequential model of the bilateral accident case. They find that an increase in injurer liability does not necessarily increase safety or efficiency in cases where the injurer is risk neutral. Complete injurer liability is found to yield Pareto optimality. When either party is risk averse, an increase in injurer liability may sometimes reduce safety and efficiency. If the injurer is risk neutral and the victim is risk averse, Pareto optimality is only achieved by assigning full liability on the injurer. If the injurer is risk averse and the victim is risk neutral, no level of injurer liability is optimal. In this case, optimality can only be achieved through the contractualization of abatement activities.

On the other hand, the standard risk-free world also requires that each party (the injurer as well as the victim(s)) have the same knowledge and/or perception of the risk of accident, and that this knowledge is consistent with a Bayesian representation (probabilistic sophisticated using Sarin and Wakker (2000)'s words). Several authors have recently relaxed such an assumption ${ }^{2}$.

Bigus (2006) discusses the functioning of tort law, when tortfeasors have preferences satisfying the axioms of the Prospect Theory. He finds, to the extend that high probabilities are under-estimated while low ones are over-estimated,

\footnotetext{
${ }^{1}$ Remark that such larges losses are typically cases for injurers judgment proofness (Shavell (1986) - an injurer is said to be judgment proof if his assets are insufficient to compensate the harm that he has caused.

${ }^{2}$ Dari-Mattiacci (2005) and de Geest and Dari-Mattiacci (2005) consider the different issue of Court's biases in the determination of liability.
} 
that the level of care obtained under strict liability is too low as compared to the efficient one; in contrast, negligence may reach the first best. Eide (2006) finds similar results when wrongdoers have preferences corresponding to the Rank Dependent Expected Utility Theory. That Prospect Theory and Rank Dependent Expected Utility Theory yield similar predictions is no surprise: both rest on the behavioral assumption that individuals distort probabilities in order to assess the weight of likelihood associated to random events to which they are faced. Moreover, both may be described in terms of a very similar axiomatic: Cumulative Prospect Theory suggested by Wakker and Tversky (1993) is a generalization of both; it states that there exist two paired functions, a probability function and a utility function on outcomes, defined on the one hand for gains (positive outcomes) and on the other for losses (negative outcomes). Specifically, the shape of the probability function looks like the one in graph 1 . This one illustrates the restrictions required to explain the typical patterns of behavior observed in experimental works, i.e. individuals undertake risk seeking decisions when they face low probabilities of winning or large probabilities of loosing, and simultaneously, they follow risk averse behavior when they face small probabilities of losses or large probabilities of gains (Tversky and Wakker (1995), Abdellaoui (2000), Stott (2006)). In some sense, such a typical probability transformation phenomenon is also observed when people have to assess the risks of several fatal hazards to which they may be faced during their lifetime (see Lichtenstein and ali (pages 565-566, 1978) for mortality risks).

In words, what is observed in various contexts including hypothetical choices (in experimental settings) or effective ones (like insurance coverage, labor supply and so on) is a tendency to under estimate events associated to a large likelihood of occurrence, and at the same time to over assess the value of small probability events.

GRAPH 1 : A typical probability distorsion function 


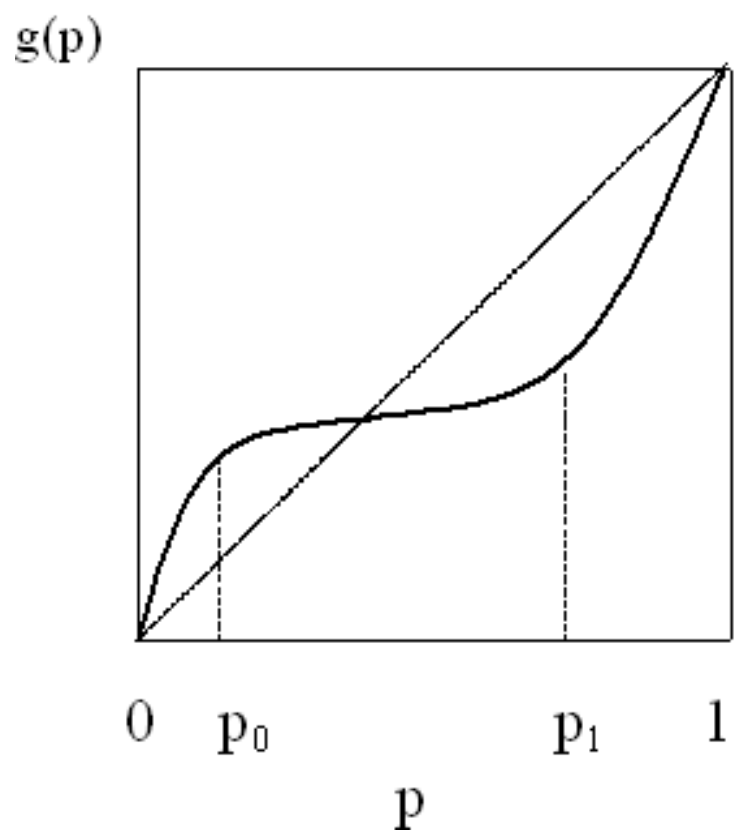

Teitelbaum (2007) uses a slightly different model of the a unilateral accident, which introduces ambiguity in the knowledge of the probability of accident. The injurer's beliefs are represented by a neo-additive capacity (Chateauneuf and ali (2003)): the functional representing his preferences is thus defined as the weighted sum of the best, worst and expected outcomes associated to the ambiguous prospect he faces. In the two-states model, this implies that the injurer under estimates the probability of the accidental event ${ }^{3}$. Then, Teitelbaum shows that neither strict liability nor negligence is generally efficient in the presence of ambiguity. More generally, he finds that the injurer's level of care decreases (increases) with ambiguity if he is optimistic (pessimistic) and decreases (increases) with his degree of optimism (pessimism). However, due to the influence of pessimism, his results suggest once more that negligence may be superior to strict liability in the unilateral accident context.

A common feature of these three papers is that they rest on the commonplace definition of the first best efficient, level of care - this last one only depends on the characteristics of the technology of safety which is available in the economy (see condition (1)). In other words, although individuals (tortfeasors, but also maybe, victims) are assumed to have a subjective assessment of the risk of

\footnotetext{
${ }^{3}$ This kind of assumption allows to solve the Ellsberg paradox. But its main weakness is that, when the ambiguity vanishes the decision context becomes risky, i.e. when the knowledge of the true probability is perfect, the model reduces to the Expected Utility one: the individual does not distort the probability of accident. Typically, there exit cumulative evidence that this is not true (see Allais's paradox): people distort objectively known probabilities. A classical presentation is Machina (1987).
} 
accident - or even more, an ambiguous information, the social planner is supposed to ignore the existence of such difficulties when it proceeds to the choice of the first best care. In the view of a benevolent planner, this may be uneasy to justify. Typically, the existence of individual biases in risks perception, or the existence of ambiguity in information, are a major concern and drawback for the implementation of public policies in the area of safety, health and/or environment regulations ${ }^{4}$. Moreover, both are a source of major imperfections in financial as well as insurance markets. For example, it is now well documented that both the demand and the supply sides in insurance markets are so sensible to them (Hogarth and Kunreuther $(1985,1989)$, Kunreuther and ali $(1993,1995))$ that they may result in severe market failure in insurance lines. As a result, insurance coverage is available but for high premia, and indemnity schedules are characterized by fixed reimbursements, or deductibles on small losses and caps and upper limits on large ones, implying that the demand side is constrained and full insurance is not possible ${ }^{5}$. The existence of imperfect insurance markets which provides individuals with limited opportunity of risk exchanges, becomes a main concern for the control of risky activities.

Hence, the analysis of prevention and the functioning of tort laws (liability rules) has to be developed with reference to situations where, due to ambiguous information and/or biases in risk perception, there exist only limited opportunities to reallocate risks in the economy - thus, the issue of risk sharing and the level of safety in the economy are not more perfectly separable, but they have in contrast to be jointly solved. This is the issue of the present paper, when accidents only represent monetary losses for the victims.

\section{$3 \quad$ Efficient risk sharing rules and safety activity}

\subsection{A simple model}

We consider a simple society with two different groups of identical individuals, injurers and victims, who are initially endowed with wealth $w=w_{0}$ and $y=y_{0}$, respectively ${ }^{6}$. Note that $W_{0}=w_{0}+y_{0}$ represents society's initial aggregate wealth - henceforth simply society's wealth. An injurer's activity may result in an accident with an exogenous probability $p>0$; if an accident occurs, a victim suffers a pecuniary loss $h(x)$, which depends on the injurer's pecuniary investment in care $x$, with $h^{\prime}(x)<0, h^{\prime \prime}(x)>0, h(0)=H>0$, and $h^{\prime}(\infty) \rightarrow 0$. Note that we assume that it is always profitable both for the injurer and for society that the injurer undertakes such an activity. However, our analysis does not address questions concerning the optimal level of activity.

\footnotetext{
${ }^{4}$ See Viscusi and ali (2000) for empirical/practical discussions, and Etner and ali (2007), Jeleva and Rossignol (2009) and Salanié and Treich (2009) for more formal arguments

${ }^{5}$ Carlier and ali (2003) provide an analysis of the design of efficient insurance contracts when insurees are Choquet Expected Utility maximizers.

${ }^{6}$ This case with only two individuals is for expositional convenience. The generalisation for $N$ agents (victims and/or injurers) is straightforward.
} 
We employ a RDEU representation of individuals' preferences (see appendix for a general presentation). We assume that both have the same probability transformation function, denoted $\varphi:[0,1] \times[0,1] \rightarrow[0,1]$ unique, continuous, increasing and convex in $p$, with $\varphi(0)=0$ and $\varphi(1)=1$. In contrast, we assume that they are characterized by a specific utility index; $u\left(w_{i}\right)$ and $v\left(y_{i}\right)$ will denote the injurer's and the victim's utility in state $i$, which are functions of their respective wealth, with $u^{\prime}, v^{\prime}>0$ and $u^{\prime \prime}, v^{\prime \prime} \leq 0-$ and $i=b$ in the accident state (the "bad" state) and $i=g$ in the no-accident state (the "good" state). Note that according to the assumption made on the various functions ( $\varphi$ convex and $u$ and $v$ are both concave), both individuals are risk averse in the strong sense, i.e. to second dominance order shifts in risk (Chew, Karni and Saffra (1987)).

Note that as compared to the shape of the probability transformation in graph 1 , we focus on the case where individuals always distort probabilities in a pessimistic way, i.e. $\varphi(p)<p \forall p \in] 0,1$ [. The main consequence of such an assumption is that they have a subjective assessment of the likelihood of accident which is larger than the true (objective, as given by statistical estimates) probability: $p<1-\varphi(1-p)$.

We will first consider the problem of a benevolent social planner, which has to choose a certain level of care $x$ and a certain allocation of risk $\left(w_{b}, w_{g} ; y_{b}, y_{g}\right)$. The planner's objective is to maximize social welfare, defined as follows:

$S W=\left\{\begin{array}{lll}(1-\varphi(1-p))\left[u\left(w_{b}\right)+v\left(y_{b}\right)\right]+\varphi(1-p)\left[u\left(w_{g}\right)+v\left(y_{g}\right)\right] & \text { if } & w_{b}<w_{g}, y_{b}<y_{g} \\ \varphi(p)\left[u\left(w_{b}\right)+v\left(y_{b}\right)\right]+(1-\varphi(p))\left[u\left(w_{g}\right)+v\left(y_{g}\right)\right] & \text { if } & w_{b}>w_{g}, y_{b}>y_{g}\end{array}\right.$

subject to the resource constraints $w_{b}+y_{b}=w_{0}+y_{0}-h(x)-x$, in the bad state, and $w_{g}+y_{g}=w_{0}+y_{0}-x$, in the good state. Note that in our analysis, we do not introduce the usual aggregate constraint: $p\left(w_{b}+y_{b}\right)+(1-p)\left(w_{g}+y_{g}\right)=$ $w_{0}+y_{0}-p h(x)-x$ : this one fits typically a situation with pure idiosyncratic risks (thus, allowing full mutualization), for which the aggregate wealth of the economy is constant over the states of the world (i.e. the constant probability of accident is close to the proportion on the population injured in each state). In such a world, it is well known (Magill and Quinzii (1996)) that (complete) contingent markets may be replaced by a perfect insurance market which pays full insurance to all individuals, and charges a premium equal to the expected indemnity. In contrast, we focus on a situation where there is an aggregate risk, which is not fully diversifiable.

\subsection{A general characterization of the first-best}

Basically, our model illustrates that in situations where an aggregate risk exists, the separation between the allocation of risk and care does not hold; thus the first best is characterized by a certain level of care $x$ and a certain sharing of the aggregate risk in each state $\left(w_{b}, w_{g} ; y_{b}, y_{g}\right)$ which maximize (2). In this section, we examine the characteristics of the first best.

Accidents reduce the aggregate wealth of society. However, this loss can in 
principle be allocated in many different ways between the parties involved. The following proposition puts some restrictions on such feasible allocations of risk.

Proposition 1 The first-best allocation of risk $\left[\left(w_{b}, w_{g}\right) ;\left(y_{b}, y_{g}\right)\right]$ is comonotonic: $w_{b} \leq w_{g}$ and $y_{b} \leq y_{g}$, and satisfies Borch's conditions, $u^{\prime}\left(w_{b}\right)=v^{\prime}\left(y_{b}\right)$ and $u^{\prime}\left(w_{g}\right)=v^{\prime}\left(y_{g}\right)$.

Proof. Assume first that there exists some values of $x>0$ such that $h(x)+$ $x<H$. Assume now that the feasible allocation $\left[\left(w_{b}, w_{g}\right) ;\left(y_{b}, y_{g}\right)\right]$ with $w_{b} \leq w_{g}$ and simultaneously $y_{b} \geq y_{g}$, associated to a care level $x$, is Pareto optimal.

Now for the same level of care, define an alternative feasible allocation $\left[\left(\tilde{w}_{b}, \tilde{w}_{g}\right) ;\left(\tilde{y}_{b}, \tilde{y}_{g}\right)\right]$ where $\tilde{w}_{b} \leq \tilde{w}_{g}$ and simultaneously $\tilde{y}_{b}=\tilde{y}_{g}$, such that:

$$
\begin{aligned}
\tilde{w}_{b} & =w_{b}+(1-p)\left(y_{b}-y_{g}\right) \\
\tilde{w}_{g} & =w_{g}-p\left(y_{b}-y_{g}\right) \\
\tilde{y}_{b} & =p y_{b}+(1-p) y_{g}=\tilde{y}_{g} \\
\tilde{w}_{b}+\tilde{y}_{b} & =w_{b}+y_{b} \\
\tilde{w}_{g}+\tilde{y}_{g} & =w_{g}+y_{g}
\end{aligned}
$$

By definition, both individuals obtain the same expected individual wealth irrespective of the allocation we choose, since: $p \tilde{y}_{b}+(1-p) \tilde{y}_{g}=p y_{b}+(1-p) y_{g}$ for the victim and $p \tilde{w}_{b}+(1-p) \tilde{w}_{g}=p w_{b}+(1-p) w_{g}$ for the injurer.

On the other hand, $\left(\tilde{w}_{b}, \tilde{w}_{g}\right)$ is less spread than $\left(w_{b}, w_{g}\right)$ in the sense of the second stochastic dominance order, since given that for the same probabilities $(p, 1-p)$ we have the following order for injurer's wealth in the different states: $w_{b}<\tilde{w}_{b} \leq \tilde{w}_{g}<w_{g} ;\left(\tilde{y}_{b}, \tilde{y}_{g}\right)$ is also less spread than $\left(y_{b}, y_{g}\right)$ since we have: $y_{b}>\tilde{y}_{b}=\tilde{y}_{g}>y_{g}$. Recall that, by assumption, both individuals are risk averse to second dominance order shifts in risk. Thus $\left[\left(\tilde{w}_{b}, \tilde{w}_{g}\right) ;\left(\tilde{y}_{b}, \tilde{y}_{g}\right)\right]$ Pareto dominates $\left[\left(w_{b}, w_{g}\right) ;\left(y_{b}, y_{g}\right)\right]$; hence a contradiction.

Now, define two real numbers $\sigma_{b}$ and $\sigma_{g}$ as the shadow prices of the aggregate resource constraints of society. The problem of the social planner is now equivalent to the maximization of:

$$
(1-\varphi(1-p))\left[u\left(w_{b}\right)+v\left(y_{b}\right)\right]+\varphi(1-p)\left[u\left(w_{g}\right)+v\left(y_{g}\right)\right]
$$

under the resources constraints. When an interior solution exists, then it corresponds to a vector $\left(x, w_{b}, w_{g}, y_{b}, y_{g}\right)$ which satisfies the set of the following conditions:

$$
\begin{array}{r}
-\sigma_{b} h^{\prime}(x)-\left(\sigma_{g}+\sigma_{b}\right)=0 \\
(1-\varphi(1-p)) u^{\prime}\left(w_{b}\right)-\sigma_{b}=0 \\
\varphi(1-p) u^{\prime}\left(w_{g}\right)-\sigma_{g}=0 \\
(1-\varphi(1-p)) v^{\prime}\left(y_{b}\right)-\sigma_{b}=0 \\
\varphi(1-p) v^{\prime}\left(y_{g}\right)-\sigma_{g}=0
\end{array}
$$


Conditions (4) to (7) define the rule that should be used by the planner to implement a first best allocation of risk. Using (4) and (6) together, and (5) and (7) together, we obtain Borch's conditions:

$$
\begin{aligned}
& u^{\prime}\left(w_{b}\right)=v^{\prime}\left(y_{b}\right), \text { with } w_{b}+y_{b}=w_{0}+y_{0}-x-h(x) \\
& u^{\prime}\left(w_{g}\right)=v^{\prime}\left(y_{g}\right), \text { with } w_{g}+y_{g}=w_{0}+y_{0}-x
\end{aligned}
$$

which leads to:

$$
\frac{v^{\prime}\left(y_{g}\right)}{v^{\prime}\left(y_{b}\right)}=\frac{u^{\prime}\left(w_{g}\right)}{u^{\prime}\left(w_{b}\right)}
$$

Now summing over conditions (4) to (7) yields:

$$
\sigma_{b}+\sigma_{g}=(1-\varphi(1-p)) v^{\prime}\left(y_{b}\right)+\varphi(1-p) v^{\prime}\left(y_{g}\right)
$$

Substituting in (3) and rearranging, we obtain that the first-best level of care satisfies the condition:

$$
-(1-\varphi(1-p)) h^{\prime}\left(x^{*}\right)+\varphi(1-p)\left(1-\frac{v^{\prime}\left(y_{g}\right)}{v^{\prime}\left(y_{b}\right)}\right)=1
$$

i.e. the efficient level of care $x^{*}$ is such that the planner weighs the victim's subjective expected benefit coming from the loss reduction (first term in the LHS of equality) adjusted now by a measure of the risk (second term in the LHS) and the marginal cost of care borne by the injurer (RHS). Condition (9) is equivalent to:

$$
h^{\prime}\left(x^{*}\right)+1=-\frac{\varphi(1-p)}{1-\varphi(1-p)} \frac{v^{\prime}\left(y_{g}\right)}{v^{\prime}\left(y_{b}\right)}
$$

which allows to show that at optimum: $h^{\prime}(x)+1<0$ (since the RHS is negative): i.e. the total cost of accident (damage to the victim + cost of care) is decreasing at optimum.

Finally, second order conditions require the following inequality to hold:

$$
\frac{h^{\prime \prime}\left(x^{*}\right)}{1+h^{\prime}\left(x^{*}\right)}\left(t_{g}^{u}+t_{g}^{v}\right)+\frac{t_{g}^{u}+t_{g}^{v}}{t_{b}^{u}+t_{b}^{v}}\left(1+h^{\prime}\left(x^{*}\right)\right)-1<0
$$

where: $t_{g}^{v}=-\frac{v^{\prime}\left(y_{g}\right)}{v^{\prime \prime}\left(y_{g}\right)}, t_{b}^{v}=-\frac{v^{\prime}\left(y_{b}\right)}{v^{\prime \prime}\left(y_{b}\right)}, t_{g}^{u}=-\frac{u^{\prime}\left(w_{g}\right)}{u^{\prime \prime}\left(w_{g}\right)}, t_{b}^{u}=-\frac{u^{\prime}\left(w_{b}\right)}{u^{\prime \prime}\left(w_{b}\right)}$ denote the inverse of the indexes of risk aversion ${ }^{7}$ for the victim and the injurer, evaluated

\footnotetext{
${ }^{7}$ Our terminology is quite abusive. In the RDEU model, the local characterization of risk aversion (or its local measure à la Arrow-Pratt) do not necessarily require the concavity of the utility index (see Chateauneuf and Cohen (1993), Cohen (1995) and Courtault and Gayant (1998)). In the sense of Segal and Spivak (1990), the RDEU model displays first order risk aversion, due to the convexity of $\varphi$; in contrast, the index $-\frac{u^{\prime \prime}}{u^{\prime}}$ corresponds to second order risk aversion (this is a second order term) which is specific to the Expected Utility model. More generally, since Allais it is a matter of debate in decision theory (see Bouyssou and Vansnick (1990)) that the concavity of the utility index represents both the risk aversion assumption (a behavior under risk) and the hypothesis of the decreasing marginal utility of a wealth (a feature of preferences with respect to certain outcomes). However, in order to keep
} 
for each state; given the various conditions made on preferences and on the technology of safety, this last inequality is obviously satisfied.

In the literature on risk sharing, the property of comonotonicity is also termed the Mutuality Principle. Its first statements are due to Borch (1962) and Arrow (1964) in the specific case of insurance arrangements (including the administrative costs of insurance contracts). Landsberger and Meilijson (1994), and Chateauneuf, Dana and Tallon (2000) provide additional insights for economies without transaction costs (expenditures needed for the sharing of aggregate resources of society) but when individuals are Non Bayesian (Non Expected Utility) maximizers. Thus our result shows that the principle also applies when costly prevention activities are considered. Note, however, that to the extent that we consider only an interior solution, not all comonotonic allocations are efficient - but only those comonotonic allocations that satisfy Borch's conditions. Such conditions yield that an efficient allocation of risk is reached when, in each state, the aggregate social wealth is shared so that the injurer's marginal utility of wealth equals the victim's marginal utility of wealth.

Since conditions (1) and (9) are quite different generally speaking (hence the two level of care are different), an important question arises here: how risk aversion affects the efficient level of care? In our companion paper (DariMattiacci and Langlais (2009)) we proved that when accidents entail some non monetary losses (which are not insurable), there is no simple answer to such question: state-dependent risk aversion may lead to a higher or a lower level of care than in a risk neutral world. In contrast, our result regarding the influence of risk aversion per se is non ambiguous here:

Proposition 2 The first-best level of care when society is risk averse is greater than when society is risk-neutral.

Proof. Risk neutrality under the RDEU representation of preferences requires that $\varphi(p)=p \forall p$ and at the same time $v^{\prime \prime}(y)=u^{\prime \prime}(w)=0 \forall y, w$. Now, note that according to proposition 1: $y_{g} \geq y_{b}$; thus, the concavity of $v$ implies $v^{\prime}\left(y_{g}\right) \leq v^{\prime}\left(y_{b}\right)$, and thus, $\varphi(1-p)\left(1-\frac{v^{\prime}\left(y_{g}\right)}{v^{\prime}\left(y_{b}\right)}\right)>0$ at optimum. Moreover, since by convexity of $\varphi$ we have: $\varphi(1-p)<1-p \Rightarrow 1-\varphi(1-p)>p$, it comes that $-(1-\varphi(1-p)) h^{\prime}(x)>-p h^{\prime}(x)$. As a result, the LHS in (9) satisfies $-(1-\varphi(1-p)) h^{\prime}(x)+\varphi(1-p)\left(1-\frac{v^{\prime}\left(y_{g}\right)}{v^{\prime}\left(y_{b}\right)}\right)>-p h^{\prime}(x)$, which allows to compare (1) and (9). Given that by convexity of $h$, the LHS in (9) decreases in $x$, we obtain $x^{*}>\hat{x}$.

easier the interpretation if the results, we make use here of the widely spread terminology, assuming that the ratio $-\frac{u^{\prime \prime}}{u^{\prime}}$ is driving the behavior under risk with respect to the variation of his wealth. Courtault and Gayant (1998) suggest that in the RDEU model, the ratio $-\frac{u^{\prime \prime}}{u^{\prime}}$ is a measure of spreading risk aversion: < the decrease of marginal utility induces mechanically a gap between the certainty equivalent of a random variable and its expectation (Courtault and Gayant (p 212, 1998)) >>. 
The condition (9) means that the optimal level of care $x^{*}$ minimizes the cost of accident adjusted for the risk; this implies that the first-best level of care $x^{*}$ for a RDEU utility-based economy is greater than the first-best level of care $\hat{x}$ in a risk-neutral economy.

Despite we obtain a different result in our companion paper (Dari-Mattiacci and Langlais (2009)), it is important to note that other general features of the first best also hold here, which are in contrast to the risk-free world:

- in relation to the parties' wealth, neither the injurer nor the victim obtains full insurance, that is, neither of them obtains the same wealth in the bad state as in the good state; moreover, in relation to the parties' utility, neither the injurer nor the victim is protected against adverse changes in his utility, that is the utility is necessarily less in the bad state than in the good state.

- care expenditures are a cost both in the good state and in the bad state, while reducing the magnitude of the loss in the bad state only. Thus, care entails an implicit transfer from the good state to the bad state, such that at optimum the total cost in case of accident (care + damage) decreases.

- the choice of the level of care is no longer independent from the choice of the allocation of risk, since the choice of the level of care implies a wealth effect through the cost of care and the accident loss. Such wealth effects cannot be undone by insurance or redistribution since, as a result of the accident, individuals find themselves in an inferior state.

The following corollary clarifies the role of risk-aversion in determining the first-best level of care, when accidents yield only monetary losses.

Corollary 3 If at least one of the parties is risk-neutral then the first-best level of care is the same as in the risk-neutral world, and any feasible allocation $\left[\left(w_{b}, w_{g}\right) ;\left(y_{b}, y_{g}\right)\right]$ providing full insurance to the victim $\left(y_{b}=y_{g}\right)$ is first best efficient.

Proof. Assume that the injurer is risk neutral: this implies that he has the identity function as a probability transformation $\varphi(p)=p$, and a constant marginal utility for wealth: $u^{\prime}\left(w_{g}\right)=$ constant $=u^{\prime}\left(w_{b}\right)$; in this case, any efficient allocation of risk fully insures the risk averse individual; thus, optimal care is independent from risk sharing and satisfies condition (1). The same result applies by symmetry when the victim is risk-neutral.

The logic of this result is that the risk-neutral party can indemnify the riskaverse party, countering the effect of risk aversion. Thus, the relevant factors determining the level of care are the same as in a risk-free or risk neutral world.

Finally, it is also worth to highlight the specific role of the pessimistic transformation of probability captured by the RDEU representation of preferences. Remark that assuming a constant marginal utility in wealth for both individuals, but maintaining the assumption that both are pessimistic $(\varphi(p)$ convex $\forall p \in[0,1])$, we obtain the specific case of the RDEU model termed as the Dual 
Theory suggested by Yaari (1987). Interestingly, the convexity of $\varphi$ is equivalent to the risk aversion assumption (Roël (1987), Yaari (1987)). A major implication of this assumption is the following:

Corollary 4 If both parties have identical preferences satisfying the axiomatic of the Dual Theory, any comonotonic allocation of wealth is first best efficient, and the optimal level of care is larger than in the risk-neutral case. Moreover, it increases with the society's pessimism.

Proof. The allocation of risk (individual wealths) is now undetermined since both are immune against marginal changes in wealth and both have the same pessimistic assessment of the probability of accident, this implies that any comonotonic allocation of the aggregate wealth (aggregate risk) may be implemented. Using that $v^{\prime}\left(y_{g}\right)=$ constant $=v^{\prime}\left(y_{b}\right)$, this implies that according to (9) the efficient care level satisfies now:

$$
-(1-\varphi(1-p)) h^{\prime}\left(x_{\varphi}\right)=1
$$

Given that $1-\varphi(1-p)>p$, then it is still true that: $x_{\varphi}>\hat{x}$.

Now, consider two different economies, characterized respectively by the pessimistic transformations $\varphi$ and $\psi$; assume that $\psi$ is a positive and convex transformation of $\varphi$ : by definition (Roël (1987) and Yaari (1987)), $\psi$ is more pessimistic than $\varphi$ (and thus, more risk averse in the sense of the Dual Theory); thus, for all $p \in[0,1]$, we have: $\varphi(p)>\psi(p)$. Finally, this implies that the society with $\psi$ has a care level which satisfies:

$$
-(1-\psi(1-p)) h^{\prime}\left(x_{\psi}\right)=1
$$

Since $1-\varphi(1-p)<1-\psi(1-p)$, we obtain that: $x_{\varphi}<x_{\psi}$.

Remark that, under the assumption that a benevolent planner acts for so$\operatorname{ciety}^{8}$, we obtain a result which is different as compared to Bigus (2006), Eide (2005), or Teitelbaum (2007), in several respects. Given that we consider a case with aggregate risk, our characterization of the first best care yields a level different than in the risk-free case (1). Moreover, it is also worth noticing that under our RDEU representation of preferences, due to the pessimism of individuals, our first best level of care is higher than in the standard risk neutral case. It is also higher than under the alternative characterization of pessimism introduced by Teitelbaum (2007). The basic reason is that under the representation based on a neo additive-additive capacity, the perceived (ambiguous and subjective) likelihood of accident is smaller than the true probability - thus, the benefits of the prevention are under estimated; in contrast, under the RDEU representation with a pessimistic transformation function, the subjective believe on the

\footnotetext{
${ }^{8}$ Etner and ali (2007) elaborate on the problem of voluntary contributions to environment; they consider a case of a planner endowed with its own preferences, represented by a probability transformation function which is different as compared to the citizens'one.
} 
likelihood of accident is larger than the true probability: thus, the benefits of prevention are over estimated as compared to the expected benefits. Finally, as society is more pessimistic, the care level moves away from the risk neutral one - while it becomes closer under the neo additive capacity representation.

However, note that under the general RDEU representation (i.e. assuming $\varphi$ convex and $u$ concave), an increase in society's pessimism will have an ambiguous effect on care. To see this, let us assume once more an economy with the same features (identical individuals) as before, excepted the probability transformation which is now described by the function $\psi$. It satisfies the same general assumptions as $\varphi$, but for all $p \in[0,1]$, we have: $\varphi(p)>\psi(p)$. Then, it corresponds to an efficient level of care $x^{* *}$ which satifies now:

$$
-(1-\psi(1-p)) h^{\prime}\left(x^{* *}\right)+\psi(1-p)\left(1-\frac{v^{\prime}\left(y_{g}\right)}{v^{\prime}\left(y_{b}\right)}\right)=1
$$

to be compared to (9). As far as $\psi(p)<p$ for all $p \in[0,1]$, it comes that $1-\psi(1-p)>1-\varphi(1-p)$ but $\psi(1-p)<\varphi(1-p)$. This implies that we may obtain $x^{*} \gtrless x^{* *}$.

\subsection{Properties of the first best: comparative statics}

The main consequence of our previous findings is that the choice of an efficient level of safety (prevention activity) is not independent of the choice of the efficient allocation of risk (allocation of the consequences of the accidents). Both are inter-related, once we recognize the existence of the aggregate risk, and the limited opportunities to reallocate it among the society. We study here some more specific properties of the social optimum: how it relates to the aggregate wealth and to the occurrence of accidents ${ }^{9}$.

\subsubsection{The role of society's wealth}

From an intuitive (naïve ?) point of view, it seems obvious that the first-best level of care increases when society's wealth increases - thus rich societies would have the opportunity to invest more in safety activities than poorer ones, and be better off this way since the consequences of accidents (damages) are reduced. The next result shows that things are less clear that it seems at first glance:

Proposition 5 Consider any first best in terms of safety activity and risk sharing. Then:

i) If both individuals have constant absolute risk aversion (CARA), then the first-best level of care is independent from society's wealth.

ii) If both individuals have decreasing absolute risk aversion (DARA), then the first-best level of care decreases in society's wealth.

\footnotetext{
${ }^{9}$ The reader will observe that our results regarding the comparative statics of care having the properties of a self-insurance activity are quite simple, and generally, easy to sign. This is in contrast to the analysis of self-protection activities, which generally yields ambiguous results or much more uneasy to interprete; see the literature in the individual context: Chiu (2000), Jullien and ali (1999), Lee (1998, 2005), Sweeney and Beard (1992).
} 
iii) If both individuals have increasing absolute risk aversion (IARA), then the first-best level of care increases in society's wealth.

Proof. Society's initial wealth is $W_{0}=w_{0}+y_{0}$. Given that according to the resources constraints, we have:

$$
\begin{aligned}
\frac{\partial y_{b}}{\partial W_{0}}+\frac{\partial w_{b}}{\partial W_{0}} & =1-\left(1+h^{\prime}(x)\right) \frac{\partial x}{\partial W_{0}} \\
\frac{\partial y_{g}}{\partial W_{0}}+\frac{\partial w_{g}}{\partial W_{0}} & =1-\frac{\partial x}{\partial W_{0}}
\end{aligned}
$$

the impact of an increase in $W_{0}$ on the individual endowments (risk sharing rules) may be obtained by first totally differentiating Borch's conditions, to obtain:

$$
\begin{aligned}
& u^{\prime \prime}\left(w_{b}\right) \frac{\partial w_{b}}{\partial W_{0}}=v^{\prime \prime}\left(y_{b}\right) \frac{\partial y_{b}}{\partial W_{0}} \Rightarrow \frac{\partial y_{b}}{\partial W_{0}}=\frac{t_{b}^{v}}{t_{b}^{u}} \frac{\partial w_{b}}{\partial W_{0}} \\
& u^{\prime \prime}\left(w_{g}\right) \frac{\partial w_{g}}{\partial W_{0}}=v^{\prime \prime}\left(y_{g}\right) \frac{\partial y_{g}}{\partial W_{0}} \Rightarrow \frac{\partial y_{g}}{\partial W_{0}}=\frac{t_{g}^{v}}{t_{g}^{u}} \frac{\partial w_{g}}{\partial W_{0}}
\end{aligned}
$$

and substituting the results of the derivation of the constraints, we obtain:

$$
\begin{aligned}
\frac{\partial y_{b}}{\partial W_{0}} & =\frac{t_{b}^{v}}{t_{b}^{u}+t_{b}^{v}}\left(1-\left(1+h^{\prime}\left(x^{*}\right)\right) \frac{\partial x^{*}}{\partial W_{0}}\right) \\
\frac{\partial y_{g}}{\partial W_{0}} & =\frac{t_{g}^{v}}{t_{g}^{u}+t_{g}^{v}}\left(1-\frac{\partial x^{*}}{\partial W_{0}}\right)
\end{aligned}
$$

Then, differentiating condition (9) and rearranging, we obtain:

$$
\frac{h^{\prime \prime}\left(x^{*}\right)}{1+h^{\prime}\left(x^{*}\right)} \frac{\partial x^{*}}{\partial W_{0}}=\frac{1}{t_{b}^{v}} \frac{\partial y_{b}}{\partial W_{0}}-\frac{1}{t_{g}^{v}} \frac{\partial y_{g}}{\partial W_{0}}
$$

After substituting (11) and (12) into (13), we have:

$$
\frac{\partial x^{*}}{\partial W_{0}}=\frac{\frac{t_{g}^{u}+t_{g}^{v}}{t_{b}^{u}+t_{b}^{v}}-1}{\frac{h^{\prime \prime}\left(x^{*}\right)}{1+h^{\prime}\left(x^{*}\right)}\left(t_{g}^{u}+t_{g}^{v}\right)+\frac{t_{g}^{u}+t_{g}^{v}}{t_{b}^{u}+t_{b}^{v}}\left(h^{\prime}\left(x^{*}\right)+1\right)-1}
$$

where: $t_{g}^{v}=-\frac{v^{\prime}\left(y_{g}\right)}{v^{\prime \prime}\left(y_{g}\right)}, t_{b}^{v}=-\frac{v^{\prime}\left(y_{b}\right)}{v^{\prime \prime}\left(y_{b}\right)}, t_{g}^{u}=-\frac{u^{\prime}\left(w_{g}\right)}{u^{\prime \prime}\left(w_{g}\right)}, t_{b}^{u}=-\frac{u^{\prime}\left(w_{b}\right)}{u^{\prime \prime}\left(w_{b}\right)}$ have been defined in the proof of proposition 1. Given that according to the second order condition associated to the first best the denominator has a negative sign, we have:

$$
\operatorname{sign} \frac{\partial x^{*}}{\partial W_{0}}=\operatorname{sign}\left(1-\frac{t_{g}^{u}+t_{g}^{v}}{t_{b}^{u}+t_{b}^{v}}\right)
$$


Now, remember that according to the Mutuality Principle, the individual endowments satisfy $w_{b} \leq w_{g}$ and $y_{b} \leq y_{g}$; hence, the individual indexes of tolerance may be ranked according to the property of the corresponding indexes of absolute risk aversion. Thus, by definition we have ${ }^{10}$ :

- under CARA: $-\frac{v^{\prime \prime}\left(y_{g}\right)}{v^{\prime}\left(y_{g}\right)}=-\frac{v^{\prime \prime}\left(y_{b}\right)}{v^{\prime}\left(y_{b}\right)}$ and $-\frac{u^{\prime \prime}\left(w_{g}\right)}{u^{\prime}\left(w_{g}\right)}=-\frac{u^{\prime \prime}\left(w_{b}\right)}{u^{\prime}\left(w_{b}\right)}$; this implies: $t_{g}^{v}=t_{b}^{v}$ and $t_{g}^{u}=t_{b}^{u} \Rightarrow \frac{t_{g}^{u}+t_{g}^{v}}{t_{b}^{u}+t_{b}^{v}}=1 \Rightarrow \frac{\partial x^{*}}{\partial W_{0}}=0 ;$

- under DARA: $-\frac{v^{\prime \prime}\left(y_{g}\right)}{v^{\prime}\left(y_{g}\right)}<-\frac{v^{\prime \prime}\left(y_{b}\right)}{v^{\prime}\left(y_{b}\right)}$ and $-\frac{u^{\prime \prime}\left(w_{g}\right)}{u^{\prime}\left(w_{g}\right)}<-\frac{u^{\prime \prime}\left(w_{b}\right)}{u^{\prime}\left(w_{b}\right)}$; this implies now $t_{g}^{v} \geq t_{b}^{v}$ and $t_{g}^{u} \geq t_{b}^{u} \Rightarrow \frac{t_{g}^{u}+t_{g}^{v}}{t_{b}^{u}+t_{b}^{v}}>1 \Rightarrow \frac{\partial x^{*}}{\partial W_{0}}<0$

- under IARA: $-\frac{v^{\prime \prime}\left(y_{g}\right)}{v^{\prime}\left(y_{g}\right)}>-\frac{v^{\prime \prime}\left(y_{b}\right)}{v^{\prime}\left(y_{b}\right)}$ and $-\frac{u^{\prime \prime}\left(w_{g}\right)}{u^{\prime}\left(w_{g}\right)}>-\frac{u^{\prime \prime}\left(w_{b}\right)}{u^{\prime}\left(w_{b}\right)}$; finally, this implies $t_{g}^{v} \leq t_{b}^{v}$ and $t_{g}^{u} \leq t_{b}^{u} \Rightarrow \frac{t_{g}^{u}+t_{g}^{v}}{t_{b}^{u}+t_{b}^{v}}<1 \Rightarrow \frac{\partial x^{*}}{\partial W_{0}}>0$.

Hence the results.

Note that we obtain a result which is in line with more commonplace analysis pertaining to insurance economics or more generally to decision making under risk, since it is well known in such literatures that wealth effects are governed at the individual level through the dependence of the index of risk aversion to the individual wealth. This property extends here to (efficient) collective decisions: the first-best level of care depends on society's wealth; however, the direction of this relation in turn depends on society's risk aversion. Thus, for richer societies it might be optimal to take more or less care than poorer societies. The intuitive explanation is as follows. As we previously observed, the technology of care allows to implement an implicit transfer of wealth from the good state to the bad state in such a risk averse and state-dependant world. According to proposition 5, wealth should be transferred to the state where (initially) society's risk aversion is the smaller; thus, increasing care is optimal if society's risk aversion is smaller in the bad state and vice versa, reversing the transfer, when the opposite applies.

Note that since Borch (1962), it is more usual in the literature on risk sharing to describe wealth effects in terms of absolute tolerance towards risk rather than in terms of absolute risk aversion. Remark that the interpretation in terms of risk aversion is specifically more relevant, but gives only a sufficient condition - in contrast, the interpretation relating on individual tolerance indexes would be more troublesome. To see this, let us denote $T_{i}$ the aggregate index of risk tolerance and $A_{i}$ the aggregate index of risk aversion in any state $i$; then straightforward manipulations show that we have: $T_{i} / A_{i}=t_{i}^{u} \times t_{i}^{v}$. In words although at the individual level, risk aversion and risk tolerance are inversely related, in contrast at the aggregate level, things are less clear. This explains that for a society to display more risk tolerance in a state, a sufficient (but not necessary) condition is that all individuals be less risk averse in that state.

\footnotetext{
${ }^{10}$ See footnote 7.
} 
Proposition 6 Any shift in the initial distribution of wealth between agents, although the aggregate wealth stays constant, has no effect on the efficient level of care, and no effect on the sharing of risk.

Proof. Consider two economies differing only with regards to the distribution of individual wealths, namely: $\left(w_{0}, y_{0}\right)$ and $\left(w_{0}^{\prime}, y_{0}^{\prime}\right)$ but such that $w_{0}+y_{0}=W_{0}=w_{0}^{\prime}+y_{0}^{\prime}$. The first best for both economies also satisfies (9)(10). Hence, they must have the same efficient expenditure in care, and must adopt the same risk sharing rules.

In words, purely redistributive changes in individuals' initial wealth that keep the initial aggregate wealth constant do not affect neither care, nor the efficient allocation of risk.

On the other hand, it is obvious that the individual first best endowments $\left(w_{b}, y_{b}, w_{g}, y_{g}\right)$ increase with $W_{0}$ : this is a straightforward result of the Mutuality Principle. The main point is: whom of both individuals should benefit more of this increase in society's wealth? Anticipating on the discussion regarding the implementation of liability rules, the question may be framed as follows: as society becomes richer, is it efficient that firm's liability in the accident increases - in the sense that the firm should borne a higher proportion of the total cost of the accident? The next proposition yields some mild conclusions:

Proposition 7 Consider any first best in terms of safety activity and risk sharing. Then, the injurer must benefit more (respectively less) than the victim of an increase in the social wealth if he is less (respectively more) risk averse than the victim.

Proof. In the proof of proposition 5, it has been shown that in each state there exists a redistributive effect, since by Borch's conditions, we also have the following relationships:

$$
\begin{aligned}
\frac{\partial y_{b}}{\partial W_{0}} & =\frac{t_{b}^{v}}{t_{b}^{u}} \frac{\partial w_{b}}{\partial W_{0}}=\frac{\left(-\frac{u^{\prime \prime}\left(w_{b}\right)}{u^{\prime}\left(w_{b}\right)}\right)}{\left(-\frac{v^{\prime \prime}\left(y_{b}\right)}{v^{\prime}\left(y_{b}\right)}\right)} \frac{\partial w_{b}}{\partial W_{0}} \\
\frac{\partial y_{g}}{\partial W_{0}} & =\frac{t_{g}^{v}}{t_{g}^{u}} \frac{\partial w_{g}}{\partial W_{0}}=\frac{\left(-\frac{u^{\prime \prime}\left(w_{g}\right)}{u^{\prime}\left(w_{g}\right)}\right)}{\left(-\frac{v^{\prime \prime}\left(y_{g}\right)}{v^{\prime}\left(y_{g}\right)}\right)} \frac{\partial w_{g}}{\partial W_{0}}
\end{aligned}
$$

This means that the way the sharing of both the cost of the accident and the cost of care depends on the ratio of the victim's tolerance to risk to the one of the injurer - or equivalently, it depends on the ratio of the victim's absolute risk aversion index to the one of the injurer. When the society becomes reacher it may be socially efficient that the injurer's allocation $\left(w_{b}, w_{g}\right)$ increases more than the victim's one $\left(y_{b}, y_{g}\right)$ yielding to a situation where the victim bears an 
increasing share of the total cost of the accident: this is typically what should occur when the victim's index of absolute risk aversion is smaller than the injurer's one in both states: $\left(-\frac{v^{\prime \prime}\left(y_{s}\right)}{v^{\prime}\left(y_{s}\right)}\right)<\left(-\frac{u^{\prime \prime}\left(w_{s}\right)}{u^{\prime}\left(w_{s}\right)}\right)$ for $s=b, g$. In words, the liability of the injurer decreases in such a case. But under the reverse conditions, it is socially efficient that the victim bears a decreasing share of the total cost of the accident such that the liability of the injurer increases in such a case.

Note that this result may appear as surprising, regarding considerations of fairness. However, the view at hand focuses on the issue of efficiency, and is not explicit regarding the specific organizations or institutions which may be adopted to implement the first best. The characterization of this last one is obtain in a general (utilitarian) context: the cost of prevention and investments in safety when these ones are interrelated to socially valuable activities, must be collectively spread. In this sense, socially efficient level of care must be set regarding both technological constraints as those coming from the available technologies of prevention, and the willingness to pay for safety of the population which depends on their preferences under risk. The argument is funded on the case where the planner has a sufficient number of instruments, and enough degree of freedom in order to implement any redistribution of costs between parties which is seen as desirable. Hence, irrespective of the specific institutions which may be created to reach it, the first best is always attainable.

\subsubsection{The influence of the probability of accidents}

The second crucial parameter of the model is the baseline risk, which is represented by the probability of accident $p$. An increase in $p$ represents an increase in risk borne by the society, in the sense of the First Stochastic Dominance the new distribution of the fatal event puts more weight of likelihood on the worst state and is also more unfavorable in expected terms (the expected damage increases), all else held equal. The issue is: what is the impact on the level of care, and on the allocation of the various costs of the accident among the society? We prove the following results:

Proposition 8 An increase in the probability of accidents leads to an increase in the first-best level of care, an increase in both individuals' wealth in the bad state, and a decrease in both individuals' wealth in the good state.

Proof. Given that $\frac{\partial y_{b}}{\partial p}+\frac{\partial w_{b}}{\partial p}=-\left(1+h^{\prime}\left(x^{*}\right)\right) \frac{\partial x^{*}}{\partial p}$ and $\frac{\partial y_{g}}{\partial p}+\frac{\partial w_{g}}{\partial p}=-\frac{\partial x^{*}}{\partial p}$, the impact on the risk sharing rules of any increase in $p$ may be obtain first totally differentiating Borch's conditions to obtain:

$$
\begin{aligned}
u^{\prime \prime}\left(w_{b}\right) \frac{\partial w_{b}}{\partial p} & =v^{\prime \prime}\left(y_{b}\right) \frac{\partial y_{b}}{\partial p} \Rightarrow \frac{\partial y_{b}}{\partial p}=\frac{t_{b}^{v}}{t_{b}^{u}} \frac{\partial w_{b}}{\partial p} \\
u^{\prime \prime}\left(w_{g}\right) \frac{\partial w_{g}}{\partial p} & =v^{\prime \prime}\left(y_{g}\right) \frac{\partial y_{g}}{\partial p} \Rightarrow \frac{\partial y_{g}}{\partial p}=\frac{t_{g}^{v}}{t_{g}^{u}} \frac{\partial w_{g}}{\partial p}
\end{aligned}
$$


and once more substituting the constraints we obtain:

$$
\left.\begin{array}{l}
\frac{\partial y_{b}}{\partial p}=-\frac{t_{b}^{v}}{t_{b}^{u}+t_{b}^{v}}\left(1+h^{\prime}\left(x^{*}\right)\right) \frac{\partial x^{*}}{\partial p} \\
\frac{\partial y_{g}}{\partial p}=-\frac{t_{g}^{v}}{t_{g}^{u}+t_{g}^{v}} \frac{\partial x^{*}}{\partial p}
\end{array}\right\}
$$

Then, differentiating condition (9) and rearranging, we obtain:

$$
\frac{h^{\prime \prime}\left(x^{*}\right)}{1+h^{\prime}\left(x^{*}\right)} \frac{\partial x^{*}}{\partial p}-\frac{1}{t_{b}^{v}} \frac{\partial y_{b}}{\partial p}+\frac{1}{t_{g}^{v}} \frac{\partial y_{g}}{\partial p}=-\frac{\varphi^{\prime}(1-p)}{(1-\varphi(1-p)) \varphi(1-p)}
$$

Substituting (15) in (16) gives:

$$
\frac{\partial x^{*}}{\partial p}=-\frac{\left(\frac{\varphi^{\prime}(1-p)}{(1-\varphi(1-p)) \varphi(1-p)}\right) \times\left(t_{g}^{u}+t_{g}^{v}\right)}{\frac{h^{\prime \prime}\left(x^{*}\right)}{1+h^{\prime}\left(x^{*}\right)}\left(t_{g}^{u}+t_{g}^{v}\right)+\frac{t_{g}^{u}+t_{g}^{v}}{t_{b}^{u}+t_{b}^{v}}\left(1+h^{\prime}\left(x^{*}\right)\right)-1}>0
$$

Coming back to (15) and remembering that at optimum we must have $-(1+$ $\left.h^{\prime}\left(x^{*}\right)\right)>0$, it comes that $\frac{\partial y_{b}}{\partial p}>0$ and $\frac{\partial y_{g}}{\partial p}<0$.

The intuition for this result is as follows: an increase in $p$ implies that the bad state becomes relatively more probable than the good state. Thus, it is optimal to transfer some wealth from the good to the bad state. This result can be achieved indirectly, by increasing the level of care, as we have already remarked. More specifically, we have shown (see (10)) that the total accident cost decreases at the first-best level of care. As a result, when care increases, the total wealth in the bad state increases, while obviously the total wealth in the good state decreases due to the investment in care. Due to the mutuality principle, since society is reacher in the bad state, so will be both individuals, and vice versa in the good state.

\subsection{Expected Utility versus Rank Dependent Expected Utility individuals}

In this paragraph, we compare our situation with risk averse RDEU individuals to a society with risk averse Expected Utility individuals - in this last one, $\varphi(p)=p \forall p \in[0,1]$; moreover, the injurer's and the victim's utility are still described by $u$ and $v$. As a result, we can apply propositions 1 to 7 for the EU economy. The main change is coming from the level of care in the EU economy, which may be characterized for example through the analogue to condition (10):

$$
h^{\prime}(\bar{x})+1=-\frac{1-p}{p} \frac{v^{\prime}\left(y_{g}\right)}{v^{\prime}\left(y_{b}\right)}
$$

Then, the fundamental result is the following: 
Proposition 9 Any feasible allocation of risk $\left(w_{b}, w_{g}, y_{b}, y_{g}\right)$ is first best efficient in the EU economy if and only if it is first best efficient in the RDEU economy. However, the first best level of care is higher in the RDEU economy than in the EU one.

Proof. A formal proof according to which a EU economy (with agents having the same probability distribution over the states) and a RDEU economy (agents having the same probability transformation function and the same probability distribution over the states) have the same set of Pareto efficient allocations of wealth may be found in Chateauneuf, Dana and Tallon (2000, proposition 3.1, corollary 3.2 and proposition 4.2) for an economy without care. It is straightforward that the result extents to economies with care, as shown in the proof of proposition 1 . Thus, let us simply consider the characterization of the efficient care level. Comparing (8) and (18), it is clear that by convexity of $\varphi$ we have $\varphi(1-p)<1-p$ and $\frac{1}{1-\varphi(1-p)}<\frac{1}{p}$ implying that $\frac{p}{1-p}>\frac{1-\varphi(1-p)}{\varphi(1-p)}$ which is equivalent to $-\frac{p}{1-p}<-\frac{1-\varphi(1-p)}{\varphi(1-p)}$. Thus, comparing (8) and (18) - the LHS $h^{\prime}(x)+1$ increases with $x$ - we obtain that the Pareto efficient levels of care satisfy: $\bar{x}<x^{*}$.

Notice that $(p, 1-p)$ is a public information in both society. Proposition 8 means that, as far as individuals have the same probability transformation, their pessimism does not alter the efficient risk sharing principles but it gives additional reasons for safety activities. More generally, it is well known for EU economies without care, and where individuals have identical priors over the states of nature, that the set of Pareto Optimal allocations of risk is independent of the priors (Chateauneuf and ali (2000), Magill and Quinzii (1996)). This implies that we also have:

Proposition 10 Consider a EU economy where the injurer's and the victim's utility are described by $u$ and $v$, both agents having the same probability distribution over the states $(q, 1-q)$; consider a RDEU economy where the injurer's and the victim's utility are described by $u$ and $v$, both agents having the same probability transformation function $\varphi$ and the same probability distribution over the states $(p, 1-p)$. Assuming $\frac{q}{1-q}=\frac{1-\varphi(1-p)}{\varphi(1-p)}$, any feasible allocation $\left(x, w_{b}, w_{g}, y_{b}, y_{g}\right)$ is first best efficient in the EU economy if and only if it is first best efficient in the RDEU economy.

This last proposition also means the following: consider two EU economies where agents are identical (same preferences, same aggregate wealth and initial endowments) excepted that in the first one the probability distribution is $(q, 1-$ $q$ ), while in the second one the probability distribution is $(1-\varphi(1-p), \varphi(1-p))$; then the set of PO allocation of risk is identical as far as $q=1-\varphi(1-p)$ and $1-q=\varphi(1-p)$. The result generalizes to economies with prevention activity, implying once more that: $\bar{x}=x^{*}$, the level of care is the same in both 
economies. As a result, the specific assumption regarding the representation of state-independent preferences may not matter so much: for any RDEU representation, there always exists an EU representation characterized by the same efficient allocation of risk and the same first-best level of risk reduction activity.

However, both economies may display some specificity. Note first that it is straightforward to verify that both share the same sensitivity to wealth effects ((14) also apply in EU economy) all else held equal. In contrast, using (17) and setting $\varphi(p)=p \forall p \in] 0,1[$, it comes that the risk sensitivity in a EU economy verifies:

$$
\frac{\partial x^{E U}}{\partial p}=-\frac{\frac{t_{g}^{u}+t_{g}^{v}}{p(1-p)}}{\frac{h^{\prime \prime}\left(x^{E U}\right)}{1+h^{\prime}\left(x^{E U}\right)}\left(t_{g}^{u}+t_{g}^{v}\right)+\frac{t_{g}^{u}+t_{g}^{v}}{t_{b}^{u}+t_{b}^{v}}\left(1+h^{\prime}\left(x^{E U}\right)\right)-1}>0
$$

Hence, the sensitivity of care to the probability of accident may be higher or smaller in the RDEU economy then in the EU economy. To see this, note that by convexity of $\varphi$, it comes that $\varphi^{\prime}(1-p)>\frac{\varphi(1-p)}{1-p} \Leftrightarrow \frac{\varphi^{\prime}(1-p)}{\varphi(1-p)}>\frac{1}{1-p}$; but given that $1-\varphi(1-p)>p \Leftrightarrow \frac{1}{1-\varphi(1-p)}<\frac{1}{p}$, we obtain that $\frac{\varphi^{\prime}(1-p)}{\varphi(1-p)} \frac{1}{1-\varphi(1-p)} \gtrless \frac{1}{p(1-p)}$ implying that all else held equal $\frac{\partial x^{*}}{\partial p} \gtrless \frac{\partial x^{E U}}{\partial p}$.

\section{Implications for the implementation of safety}

So far, we have studied care and risk-sharing policies by a benevolent planner, who can directly implement both of them. In the following, we extend the analysis to consider whether these two objectives can be reached by means of ordinary policy instruments, such as regulation, insurance, and tort liability.

\subsection{Simple regulation schemes}

The results of propositions 1 to 8 suggest that the efficient allocation of wealth is not linear, in the sense that an increase in society's wealth does not result in a proportional change in the individuals' wealth. The specific shape of this relationship depends on the curvature of individual utility functions and on the safety technology. However, for practical purposes, effective insurance policies, regulation or liability ought to be simple enough to be implemented. In this section, we show that it is possible to reach the first best by using simple linear rules governing the level of care and how the harm and the cost of care are shared between the parties.

Consider a simple sharing rule for both the harm and the cost of care, such that the injurer bears an amount $\beta h(x)$ of the harm and an amount $\alpha x$ of the cost of care. Focusing directly on the comonotonic case, the social problem consists of finding $\left(\alpha^{*}, \beta^{*}, X\right)$ that maximize:

$$
\begin{aligned}
& S W=(1-\varphi(1-p)) u\left(w_{0}-\beta h(x)-\alpha x\right)+\varphi(1-p) u\left(w_{0}-\alpha x\right) \\
& +(1-\varphi(1-p)) v\left(y_{0}-(1-\beta) h(x)-(1-\alpha) x\right)+\varphi(1-p) v\left(y_{0}-(1-\alpha) x\right)
\end{aligned}
$$


Ignoring the arguments of the utility functions, the first-order conditions yield:

$$
\begin{gathered}
u^{\prime}\left(w_{b}\right)=v^{\prime}\left(y_{b}\right) \\
(1-\varphi(1-p)) u^{\prime}\left(w_{b}\right)+\varphi(1-p) u^{\prime}\left(w_{g}\right)=(1-\varphi(1-p)) v^{\prime}\left(y_{b}\right)+\varphi(1-p) v^{\prime}(g) \\
(1-\varphi(1-p)) h^{\prime}(X)+1=\varphi(1-p)\left(1-\frac{v^{\prime}\left(y_{g}\right)}{v^{\prime}\left(y_{b}\right)}\right)
\end{gathered}
$$

with $w_{b}=w_{0}-\beta h(x)-\alpha x, w_{g}=w_{0}-\alpha x, y_{b}=y_{0}-(1-\beta) h(x)-(1-\alpha) x$ and $y_{g}=y_{0}-(1-\alpha) x$. Note that (19) requires that marginal utilities of victim and injurer in the bad state be equal; combining (19) and (20) we have also that the marginal utilities of victim and injurer in the good state should be equal: $u^{\prime}(b)=v^{\prime}(g)$, which satisfies Borch's conditions, yielding in turn that the allocation of risk is the same as in the first-best. Likewise, (21) is the same as (9), yielding that the level of care is also the same as in the first best, $X=x^{*}$. This result should not be surprising, since it is due to the fact that there are as many independent instruments as variables to control: $X$ controls care, while $\alpha^{*}$ and $\beta^{*}$ control the allocation of risk in the good and the bad state.

The solution just described may also be implemented through a mix of regulation and lump-sum transfers. Regulation sets and enforces the required level of care, while taxes and subsidies realize the desired transfers of wealth between the parties in each state. To illustrate, assume that the injurer pays both the cost of care and the accident loss, while the victim pays two different lump-sum taxes $\tau_{b}$ in the bad state and $\tau_{g}$ in the good state, which are used to subsidize the injurer. Regulation has the task to enforce the level of care $X=x^{*}$. Assuming that this goal is achieved by means of fines or other forms of punishment for violators, then the efficient choice of $\left(\tau_{b}, \tau_{g}\right)$ by the planner maximizes (once more, considering only the comonotonic case):

$$
\begin{array}{r}
S W=(1-\varphi(1-p)) u\left(w_{0}-h\left(x^{*}\right)-x^{*}+\tau_{b}\right)+\varphi(1-p) u\left(w_{0}-x^{*}+\tau_{g}\right) \\
+(1-\varphi(1-p)) v\left(y_{0}-\tau_{b}\right)+\varphi(1-p) v\left(y_{0}-\tau_{g}\right)
\end{array}
$$

and thus, the optimal values of $\left(\tau_{b}^{*}, \tau_{g}^{*}\right)$ satisfy:

$$
\begin{gathered}
u^{\prime}\left(w_{0}-h\left(x^{*}\right)-x^{*}+\tau_{b}^{*}\right)=v^{\prime}\left(y_{0}-\tau_{b}^{*}\right) \\
u^{\prime}\left(w_{0}-x^{*}+\tau_{g}^{*}\right)=v^{\prime}\left(y_{0}-\tau_{g}^{*}\right)
\end{gathered}
$$

which have the same form as Borch's conditions.

\subsection{Tort laws and liability rules}

In this context of unilateral prevention, we focus on two simple rules; strict liability and negligence, and discuss how private insurance improve the situation. 


\subsubsection{Tort law and moral constraints}

In our companion paper (Dari-Mattiacci and Langlais (2009)), we characterized a second best (Pareto-constrained) situation as one in which one party obtains full insurance against accidents (i.e. receives the same wealth, irrespective of the state of the world that materializes). We labelled this situation as a secondbest outcome since we showed that in the first best both parties should bear some risk. Fairness for example may be a justification that innocent victims do not suffer any reduction in their wealth as a consequence of accidents that they were not in a position to avoid.

One case with full insurance for the victim obtains when $\bar{y}=y_{0}$, that is, the victim is guaranteed its initial level of wealth in all states. But we are allowed to consider the general situation in which $\bar{y}>0$ is arbitrarily set. This encompasses both the case where $\bar{y}>y_{0}$ and the case where $\bar{y}<y_{0}$ : thus, the victim's wealth is constant across states $y_{b}=y_{g}=\bar{y}$ but might be either greater or less than his initial wealth. Accordingly to this Pareto-constrained solution, the injurer obtains $w_{b}=W_{0}-\bar{y}-x-h(x)$, in the bad state, and $w_{g}=W_{0}-\bar{y}-x$, in the good state.

Considering such constraints, there is no guarantee that the Borch conditions in proposition 1 are satisfied. However, such an allocation of risk enable the planer to transfer the full burden of the costs of the accident, including the risk, to the injurer. The problem of the social planer reduces to the maximization of:

$$
(1-\varphi(1-p)) u\left(W_{0}-\bar{y}-h(x)-x\right)+\varphi(1-p) u\left(W_{0}-\bar{y}-x\right)
$$

and leads the injurer's level of care, $x_{\bar{y}}$, to satisfy the following first order condition:

$$
-(1-\varphi(1-p)) h^{\prime}\left(x_{\bar{y}}\right)+\varphi(1-p)\left(1-\frac{u^{\prime}\left(W_{0}-\bar{y}-x_{\bar{y}}\right)}{u^{\prime}\left(W_{0}-\bar{y}-h\left(x_{\bar{y}}\right)-x_{\bar{y}}\right)}\right)=1
$$

Condition (22) has the same general frame as (9) excepted that Borch conditions do not hold a priori ${ }^{11}$. This means that the second best level of care depends on ${ }^{12}$ the aggregate wealth, the probability of accident, the characteristic of the technology of care, and so interestingly, the injurer's pessimism and risk aversion.

There are several reasons why firms may act as if they were risk-averse. Basic justifications refer to factors such as non-diversified ownership, the existence of liquidity constraints or the risk of bankruptcy and costly financial distress, and non-linear tax systems (Baron (1971), Leland (1972), Sandmo (1971)). In these cases, the argument is a technical one: although the firm utility index is linear in its profit (constant marginal utility), the constraints coming from the limited ability to spread risk or from the tax system, introduce a non linearity (concavity) in its objective - leading to risk averse decisions by the firms.

\footnotetext{
${ }^{11}$ Excepted by chances.

${ }^{12}$ It is easy to verify that the resulting second-best level of care has most of the characteristics found for the first best.
} 
Other reasons are linked to the delegation of control to a risk-averse manager, whose pay is linked to firm performance, which may also cause a firm to behave in a risk-averse manner: thus, the preferences of the manager are substituted with the preferences of the firm. Finally, it has been shown by Adellaoui and Munier (1997) that the specific pattern of behavior under risk captured by the RDEU assumption is observed in the area of industrial activities associated to potential major accidents, since employees including highly graduated or skilled ones (engineers, technicians) of chemical or nuclear plants exhibited a tendency to underestimate the probability of accident, leading them to undertake lower efforts of precaution than needed.

The next issue is: what are consequences of imperfect risk sharing for the setting of safety activities? We are allowed to prove the next result, where $\left(\tilde{w}_{b}, \tilde{w}_{g}, \tilde{y}_{b}, \tilde{y}_{g}\right)$ denotes the first best allocation, while $\left(w_{b}, w_{g}, \bar{y}, \bar{y}\right)$ denotes the second best one:

Proposition 11 The second best level of care may be smaller or larger than the first best one. A/ More specifically, the second best care level is larger than the first best, either: i) if $\bar{y}<\tilde{y}_{b}$ and if the injurer is IARA; or ii) if $\bar{y}>\tilde{y}_{g}$ and if the injurer is DARA. B/ Finally, if $\bar{y} \in] \tilde{y}_{b}, \tilde{y}_{g}[$, the two levels of care are not directly comparable.

Proof. Let us define the function $s(k) \equiv \frac{u^{\prime}(g+k)}{u^{\prime}(b+k)}$ where $g>b$; then if the injurer is DARA, $s(k)$ is increasing, while if the injurer is IARA, $s(k)$ is decreasing. This is straightforward since:

$$
s^{\prime}(k) \equiv \frac{u^{\prime}(g+k)}{u^{\prime}(b+k)}\left[\left(-\frac{u^{\prime \prime}(b+k)}{u^{\prime}(b+k)}\right)-\left(-\frac{u^{\prime \prime}(g+k)}{u^{\prime}(g+k)}\right)\right]
$$

and thus: $\operatorname{sign}\left[s^{\prime}(k)\right]=\operatorname{sign}\left[\left(-\frac{u^{\prime \prime}(b+k)}{u^{\prime}(b+k)}\right)-\left(-\frac{u^{\prime \prime}(g+k)}{u^{\prime}(g+k)}\right)\right]$.

By definition, the first best requires the sharing of the total cost of accident by both parties (each one bears a part of the aggregate risk, according to the Mutuality Principle), and satisfies $\tilde{y}_{b}<\tilde{y}_{g}$ and $\tilde{w}_{b}=W_{0}-\tilde{y}_{b}-h(x)-x<\tilde{w}_{g}=$ $W_{0}-\tilde{y}_{g}-x$. In contrast, should the planner adheres to moral considerations, the second best corresponds to an allocation where $y_{b}=y_{g}$ but $w_{b}=W_{0}-\bar{y}-h(x)-$ $x<w_{g}=W_{0}-\bar{y}-x$. By concavity of $u$, we also have: $\frac{u^{\prime}\left(\tilde{w}_{g}\right)}{u^{\prime}\left(\tilde{w}_{b}\right)}>\frac{u^{\prime}\left(W_{0}-\tilde{y}_{b}-x\right)}{u^{\prime}\left(W_{0}-\tilde{y}_{b}-h(x)-x\right)}$ and $\frac{u^{\prime}\left(\tilde{w}_{g}\right)}{u^{\prime}\left(\tilde{w}_{b}\right)}>\frac{u^{\prime}\left(W_{0}-\tilde{y}_{g}-x\right)}{u^{\prime}\left(W_{0}-\tilde{y}_{g}-h(x)-x\right)}$.

Consider two cases:

i) Let us define now as: $\bar{y}=\tilde{y}_{b}-k$. It comes that if the injurer is IARA, we obtain: $\frac{u^{\prime}\left(\tilde{w}_{g}\right)}{u^{\prime}\left(\tilde{w}_{b}\right)}>\frac{u^{\prime}\left(W_{0}-\tilde{y}_{b}-x\right)}{u^{\prime}\left(W_{0}-\tilde{y}_{b}-h(x)-x\right)}>\frac{u^{\prime}\left(W_{0}-\tilde{y}_{b}+k-x\right)}{u^{\prime}\left(W_{0}-\tilde{y}_{b}+k-h(x)-x\right)}$.

Hence, by continuity, for any feasible $\bar{y}<\tilde{y}_{b}$ we have under IARA: $\frac{u^{\prime}\left(\tilde{w}_{g}\right)}{u^{\prime}\left(\tilde{w}_{b}\right)}>$ $\frac{u^{\prime}\left(W_{0}-\bar{y}-x\right)}{u^{\prime}\left(W_{0}-\bar{y}-h(x)-x\right)}$. As a result, it comes that: $\varphi(1-p)\left(1-\frac{u^{\prime}\left(\tilde{w}_{g}\right)}{u^{\prime}\left(\tilde{w}_{b}\right)}\right)<\varphi(1-$ p) $\left(1-\frac{u^{\prime}\left(W_{0}-\bar{y}-x\right)}{u^{\prime}\left(W_{0}-\bar{y}-h(x)-x\right)}\right)$; hence, the LHS in (9) is smaller than the LHS in (22), and finally this implies: $x^{*}<x_{\bar{y}}$. 
ii) Let us now define as: $\bar{y}=\tilde{y}_{g}+k$. It comes that if the injurer is DARA, we obtain: $\frac{u^{\prime}\left(\tilde{w}_{g}\right)}{u^{\prime}\left(\tilde{w}_{b}\right)}>\frac{u^{\prime}\left(W_{0}-\tilde{y}_{g}-x\right)}{u^{\prime}\left(W_{0}-\tilde{y}_{g}-h(x)-x\right)}>\frac{u^{\prime}\left(W_{0}-\tilde{y}_{g}-k-x\right)}{u^{\prime}\left(W_{0}-\tilde{y}_{g}-k-h(x)-x\right)}$. Hence, by continuity, for any feasible $\bar{y}>\tilde{y}_{g}$ we have under DARA: $\frac{u^{\prime}\left(\tilde{w}_{g}\right)}{u^{\prime}\left(\tilde{w}_{b}\right)}>\frac{u^{\prime}\left(W_{0}-\bar{y}-x\right)}{u^{\prime}\left(W_{0}-\bar{y}-h(x)-x\right)}$. As a result, we have: $\varphi(1-p)\left(1-\frac{u^{\prime}\left(\tilde{w}_{g}\right)}{u^{\prime}\left(\tilde{w}_{b}\right)}\right)<\varphi(1-p)\left(1-\frac{u^{\prime}\left(W_{0}-\bar{y}-x\right)}{u^{\prime}\left(W_{0}-\bar{y}-h(x)-x\right)}\right)$; hence, the LHS in (9) is still smaller than the LHS in (22), and finally it comes also that: $x^{*}<x_{\bar{y}}$.

The main consequence of these results is that the second best care level is set according to the variation of the injurer's risk aversion index with wealth. Proposition 11 contrasts two specific cases. In the first one: $\bar{y}<\tilde{y}_{b}$, the endowment of the victim deteriorates as compared to the worst event at first best although he obtains a constant wealth, non contingent to the state of the nature. Then, the share of the aggregate risk (i.e. wealth) borne by the injurer increases: as a result, as far as the injurer is IARA, this must be compensated by a higher level of care. In the second one, $\bar{y}>\tilde{y}_{g}$, the endowment of the victim is improved as compared to the best event at first best; thus, the share of the aggregate wealth borne by the injurer now decreases: thus, under the assumption that the injurer is DARA, this also requires that more care be undertaken. ${ }^{13}$

\subsubsection{Strict liability}

We now turn to liability rules, which are alternative tools to reallocate wealth and give incentives to take care. An important result of the previous analysis is that the first best requires enough instruments to reallocate wealth across states. However, liability rules allow transfers between the injurer and the victim in the bad state - in the form of damages payments - while ruling out any payment in the good state. Thus, it may be expected that liability falls short of controlling all of the three variables pertaining to risk-sharing and care and hence will not be enough to implement the first best. In the following we also compare the performance of liability rules to the second best.

Consider first strict liability: the injurer pays damages equal to $\lambda h(x)$ whenever an accident occurs, where $\lambda>0$. With $\lambda=1$, the injurer pays perfectly compensatory damages to the victim - the victims obtains full compensation for his pecuniary losses and, thus, has a constant wealth across states $y_{b}=y_{g}=y_{0}$. However, strict liability can also be designed as to allow for supracompensatory damages $(\lambda>1$, such as punitive damages) or infracompensatory $(\lambda<1)$ damages, in which cases the victim receives a state-dependent wealth which is $y_{0}+(\lambda-1) h(x)$ in the bad state, and $y_{0}$ in the good state.

Proposition 12 Under strict liability with perfect compensatory damages $\lambda=$ 1 , the injurer chooses a second-best level of care. The associated allocation of risk

\footnotetext{
${ }^{13}$ Typically, under IARA (DARA), the injurer is less (more) prone to undertake risk when he becomes reacher (see Pratt (1964))
} 
is also second best. If damages are infra- or supracompensatory, the outcome is neither a first best nor a second best.

Proof. Assume that the liability rule is strict liability: $\lambda=1$. Under this liability rule, the injurer will take care as to maximize:

$$
(1-\varphi(1-p)) u\left(w_{0}-\lambda h(x)-x\right)+\varphi(1-p) u\left(w_{0}-x\right)
$$

Let $x_{\lambda}$ denote the injurer's level of care, which satisfies the following first order condition:

$$
-(1-\varphi(1-p)) \lambda h^{\prime}\left(x_{\lambda}\right)+\varphi(1-p)\left(1-\frac{u^{\prime}\left(w_{0}-x_{\lambda}\right)}{u^{\prime}\left(w_{0}-\lambda h\left(x_{\lambda}\right)-x_{\lambda}\right)}\right)=1
$$

Thus, when $\lambda=1$ the injurer's choice of care is the same as in the second best in (22). The wealth of the victim is thus the constant allocation $\bar{y}=y_{0}$ which provides him with full insurance. Hence, $\lambda=1$ allows to implement the second best both in terms of care and of risk.

When $\lambda \neq 1, x_{\lambda}$ does not meet the condition for a second best level of care. Moreover, such a liability rule generally does reach neither a first best nor a second best allocation of risk. With supracompensatory damages, the victim receives a greater wealth in the bad state than in the good state: $y_{0}+(\lambda-1) h(x)>$ $y_{0}=y_{g}$, implying that the associated allocation of risk is not comonotonic, hence it cannot be first-best efficient. In contrast, with infracompensatory damages we have $y_{0}+(\lambda-1) h(x)<y_{0}$; then, the allocation is comonotonic but it will be only by chance that Borch's conditions are met; moreover care is not set at the first-best level.

From this proposition it emerges that increasing or decreasing the damage amount affects both the level of care and the sharing of the risk, bringing the outcome away from the second best (but possibly improving over it), without being able to reach the first best.

\subsubsection{Negligence}

Under the negligence rule, the injurer pays damages only if negligent, that is if his level of care is below $X$. Here the only policy instrument is the due care level $X$. In fact, if the injurer abides by the standard of care, he does not pay damages to the victim, thus $\lambda$ becomes irrelevant as concerns the allocation of risk.

However, the parameter $\lambda$ is important in respect of the question of incentive compatibility. When the standard of care is set at the level $X$, the utility level of the injurer is defined as:

$U\left(w_{0}, x\right)= \begin{cases}u\left(w_{0}-x\right) & \text { if } x \geq X \\ (1-\varphi(1-p)) u\left(w_{0}-\lambda h(x)-x\right)+\varphi(1-p) u\left(w_{0}-x\right) & \text { otherwise }\end{cases}$ 
As a result, under the negligence rule, the injurer obtains a sure outcome $\left(w_{0}-X\right)$ if he adheres to the due care standard, and a risky outcome $\left(p, w_{0}-\right.$ $\left.\lambda h(x)-x ; 1-p, w_{0}-x\right)$ if he does not. Note that according to the first line of (23), the injurer has no incentives to choose $x>X$. According to the second line of (23), when he does not comply with $X$, the injurer chooses the same level of care as under strict liability; $x_{\lambda}$ denotes this level of care.

Thus, negligence raises two issues: Will the injurer comply with the due care? Assuming he does, how does the outcome compare with the first and second best? In our companion paper, we defined a dual second best, as one for which the injurer receives the same constant endowment across the states, and thus, the victim bears the full aggregate risk.

Proposition 13 Under the negligence rule with a due care standard $X$ :

i) If $X \leq x_{\lambda}$, then the injurer complies with the due care standard;

ii) If $X>x_{\lambda}$, then the injurer complies with the due care standard only if the following condition is satisfied:

$$
\begin{aligned}
& (1-\varphi(1-p)) u\left(w_{0}-\lambda h\left(x_{\lambda}\right)-x_{\lambda}\right)+\varphi(1-p) u\left(w_{0}-x_{\lambda}\right) \\
\leq & u\left(w_{0}-X\right)
\end{aligned}
$$

iii) The allocation of risk is generally not first best. If the injurer complies, the allocation of risk is dual second best.

Proof. i) If $X \leq x_{\lambda}$, then: $u\left(w_{0}-\lambda h\left(x_{\lambda}\right)-x_{\lambda}\right) \leq u\left(w_{0}-x_{\lambda}\right) \leq u\left(w_{0}-X\right)$ which implies in turn:

$$
\begin{aligned}
& p u\left(w_{0}-\lambda h\left(x_{\lambda}\right)-x_{\lambda}\right)+(1-p) u\left(w_{0}-x_{\lambda}\right) \\
\leq & (1-\varphi(1-p)) u\left(w_{0}-x_{\lambda}\right)+\varphi(1-p) u\left(w_{0}-x_{\lambda}\right) \\
\leq & (1-\varphi(1-p)) u\left(w_{0}-X\right)+\varphi(1-p) u\left(w_{0}-X\right) \\
= & u\left(w_{0}-X\right)
\end{aligned}
$$

Thus, the injurer complies with due care.

ii) if $X>x_{\lambda}$, then:

$$
\begin{aligned}
& u\left(w_{0}-x_{\lambda}\right) \\
= & (1-\varphi(1-p)) u\left(w_{0}-x_{\lambda}\right)+\varphi(1-p) u\left(w_{0}-x_{\lambda}\right) \\
\geq & (1-\varphi(1-p)) u\left(w_{0}-X\right)+\varphi(1-p) u\left(w_{0}-X\right) \\
= & u\left(w_{0}-X\right)
\end{aligned}
$$

but condition (24) is not always satisfied. In several cases, the injurer may prefer to be found liable and bear the loss rather than comply with the due care standard.

iii) When the injurer complies, the victim is not compensated for his loss. The injurer only bears the cost of care and does not face any risk. This outcome is the dual of the second best described above, where the victim did not face any risk. 
According to proposition 11, note that the results also apply when the standard is $X=x^{*}$. However, given the costs allocation associated to the negligence, the outcome in terms of risk sharing can never be first best. But it is easy to see that whatever the standard $X$, the injurer complies as far as it entails a risk reduction as compared to not complying. This requirement is obviously met once we have $X \leq x_{\lambda}$; hence, the first best in term of prevention may be obtained if $X=x^{*} \leq x_{\lambda}$. In contrast, by setting $X=x_{\lambda}$ and $\lambda=1$, the planner can reach for sure the second-best level of care $X=x_{\bar{y}}$. Concerning the allocation of risk, note the negligence rule implements a second-best allocation of risk where the injurer, rather than the victim, is fully insured. Finally, the level of care that is second best when the injurer is fully insured can be reached provided that the incentive-compatibility conditions set in the proposition above are satisfied.

\subsection{Does insurance improve the situation?}

We now consider the issue of liability and insurance combined. For the sake of simplicity, we only introduce perfect compensatory damages $(\lambda=1)$. Assume now that the injurer has the opportunity to buy third-party liability insurance in a competitive insurance market and that the insurer can cheaply control the injurer's level of care. In a private insurance market, insurers charge a premium: $m=(1+\zeta) \operatorname{tph}(x)$, with a loading factor $\zeta \geq 0$ reflecting the existence of administrative costs in the insurance sector, and pay an indemnity in case of accident $q=\operatorname{th}(x)$ where $t \in[0,1]$.

Under strict liability, the amount of insurance coverage and the level of care chosen by the injurer are the solution to the maximization of:

$$
U(t)=\left\{\begin{array}{lll}
(1-\varphi(1-p)) u\left(w_{b}\right)+\varphi(1-p) u\left(w_{g}\right) & \text { if } & q \leq h(x) \\
\varphi(p) u\left(w_{b}\right)+(1-\varphi(p)) u\left(w_{g}\right) & \text { if } & q>h(x)
\end{array}\right.
$$

defining as $w_{b}=w_{0}-h(x)+q-x-m$ and $w_{g}=w_{0}-x-m$. Note that:

$U^{\prime}(t)= \begin{cases}(1-\varphi(1-p))(1-(1+\zeta) p) u^{\prime}\left(w_{b}\right)-\varphi(1-p)(1+\zeta) p u^{\prime}\left(w_{g}\right) & \text { if } \quad q \leq h(x) \\ \varphi(p)(1-(1+\zeta) p) u^{\prime}\left(w_{b}\right)-(1-\varphi(p))(1+\zeta) p u^{\prime}\left(w_{g}\right) & \text { if } q>h(x)\end{cases}$

and that for $t \in] 0,1\left[\right.$, the equilibrium level of care $x_{\zeta}$ satisfies $^{14}$ :

$$
-(1-\varphi(1-p)) h^{\prime}\left(x_{\zeta}\right)[(1-t)+(1+\zeta) p t]+\varphi(1-p)\left(1-\frac{u^{\prime}\left(w_{g}\right)}{u^{\prime}\left(w_{b}\right)}\left[1+(1+\zeta) p t h^{\prime}\left(x_{\zeta}\right)\right]\right)=1
$$

The main results are the following:

\footnotetext{
${ }^{14}$ For an interior solution $x>0$.
} 
Proposition 14 Assume that liability coverage is offered in a private insurance market. Then, strict liability with perfect compensatory damage generally does not yield the first-best. More specifically:

A) The injurer demands full insurance if $\zeta \in\left[\frac{\varphi(p)}{p}-1, \frac{1-\varphi(1-p)}{p}-1\right]$; moreover i) if $\left.\zeta \in] 0, \frac{1-\varphi(1-p)}{p}-1\right]$, he produces a level of care higher than the risk neutral one; ii) in contrast if $\zeta \in\left[\frac{\varphi(p)}{p}-1,0\right]$, he produces a level of care smaller than the first best one.

B) The injurer demands a partial insurance contract if $\zeta>\frac{1-\varphi(1-p)}{p}-1$; i) moreover if $\zeta>\frac{1-p}{p}$, he undertakes an effort which is higher than the first best; but if $\zeta<\frac{1-p}{p}$, he undertakes an effort which may be higher or smaller than the first best.

Proof. A) It has been demonstrated in the case without care (see Dupuis and Langlais (1997)), that for RDEU agents full insurance $(t=1)$ is optimal in a range of the loading factor $\zeta$ requiring low enough values (both positive and negative $)^{15}$. The same result also holds with we consider safety activities; if $\zeta$ satisfies: $\frac{1-\varphi(1-p)}{\varphi(1-p)} \geq \frac{(1+\zeta) p}{1-(1+\zeta) p} \geq \frac{\varphi(p)}{1-\varphi(p)} \Leftrightarrow \frac{1-\varphi(1-p)}{p}-1 \geq \zeta \geq \frac{\varphi(p)}{p}-1$, the injurer will buy full insurance $t=1 \Leftrightarrow q=h(x)$. To see this, remark that according to (25) expressed at $t=1$, we have that $t=1$ is the best insurance decision for the injurer as long as:

$$
U^{\prime}(1)= \begin{cases}(1-\varphi(1-p))(1-(1+\zeta) p)-\varphi(1-p)(1+\zeta) p & >0 \\ \varphi(p)(1-(1+\zeta) p)-(1-\varphi(p))(1+\zeta) p & <0\end{cases}
$$

Then, the upper line means that as long as $\frac{1-\varphi(1-p)}{\varphi(1-p)} \geq \frac{(1+\zeta) p}{1-(1+\zeta) p} \Leftrightarrow \frac{1-\varphi(1-p)}{p}-$ $1 \geq \zeta$, then the injurer has no incentives to reduce his insurance coverage, and thus full insurance is still individually optimal; the bottom line in contrast implies that as long as $\frac{(1+\zeta) p}{1-(1+\zeta) p} \geq \frac{\varphi(p)}{1-\varphi(p)} \Leftrightarrow \zeta \geq \frac{\varphi(p)}{p}-1$, then the injurer has no incentives to increase his insurance coverage (should he have the opportunity to obtain over insurance), and thus full insurance stays individually optimal.

As a result, when $t=1$ (for which $w_{b}=w_{g}$ and thus $u^{\prime}\left(w_{b}\right)=u^{\prime}\left(w_{g}\right)$ ), condition (26) becomes:

$$
-p h^{\prime}\left(x_{\zeta}\right)(1+\zeta)=1
$$

to be compared with the first best given by (9), and to the risk-free case given by (1). It is thus straightforward that for (small but) positive values of the loading factor, $\frac{1-\varphi(1-p)}{p}-1 \geq \zeta>0$, then $x_{\zeta}>\hat{x}$ but $x_{\zeta} \lessgtr x^{*}$; on the other hand, for (small but) negative values of $\zeta, 0>\zeta \geq \frac{\varphi(p)}{p}-1$, then $x_{\zeta}<\hat{x}$ and hence $x_{\zeta}<x^{*}$. Finally, for $\zeta=0$, then we obtain $x_{\zeta}=\hat{x}<x^{*}$.

\footnotetext{
${ }^{15}$ In contrast, Mossin (1968) first established that a risk averse EU individual does not buy a full insurance contract, unless $\zeta=0$, which is the unique value for which it is optimal that $t=1$.
} 
B) In contrast, for large enough values of $\zeta$ satisfying $\zeta>\frac{1-\varphi(1-p)}{p}-1$, then following (25), the injurer will buy partial insurance $t<1 \Leftrightarrow q<h(x)$ such that:

$$
(1-\varphi(1-p))(1-(1+\zeta) p) u^{\prime}\left(w_{b}\right)-\varphi(1-p)(1+\zeta) p u^{\prime}\left(w_{g}\right)=0
$$

In this case, the level of care attained will satisfy the general expression of (25) with $w_{b}<w_{g}$. Thus, generally speaking, there is no obvious ranking of $x_{\zeta}$ against $\hat{x}$ or $x^{*}$. In order to make explicit the comparison with (9), let us rewrite (26) as:

$$
\begin{aligned}
& -(1-\varphi(1-p)) h^{\prime}\left(x_{\zeta}\right)+\varphi(1-p)\left(1-\frac{u^{\prime}\left(w_{g}\right)}{u^{\prime}\left(w_{b}\right)}\right) \\
& -(1-\varphi(1-p)) h^{\prime}\left(x_{\zeta}\right) t[(1+\zeta) p-1]-(1+\zeta) p t h^{\prime}\left(x_{\zeta}\right) \varphi(1-p) \frac{u^{\prime}\left(w_{g}\right)}{u^{\prime}\left(w_{b}\right)} \\
= & 1
\end{aligned}
$$

Remark that setting $t=0$, then (28) writes as (9). The fourth LHS term in (28) is positive; the third one is positive as far as $(1+\zeta) p>1 \Leftrightarrow \zeta>$ $\frac{1-p}{p}\left(>\frac{1-\varphi(1-p)}{p}-1\right)$. Then if $\zeta>\frac{1-p}{p}$, the level of care is higher than the first best one: $x_{\zeta}>x^{*}$. In contrast, when $\zeta<\frac{1-p}{p}$, the level of care may be higher or smaller than the first best one.

Note that the threshold loading factor $\frac{1-\varphi(1-p)}{p}-1$ is positive, given the convexity of $\varphi$; in contrast the threshold $\frac{\varphi(p)}{p}-1$ is negative, reflecting that subsidizes to insurance. The reason behind this last proposition is that insurance markets allow the injurer to individually reallocate his wealth among different states of the nature, in such a way that his marginal utility of wealth be equal between states. Nevertheless, this does not represent a Pareto efficient allocation, since according to Borch's conditions, the first best allocation of risk is only obtained through transfers between individuals, state by state, in order that individual marginal utilities equate in each separate state. As a result, the decentralization of the choice for the prevention activity leads the injurer to finally invest in care depending only on his own situation and characteristics.

Consider now the simple negligence when the standard of care (and perfect compensatory damages) is set at the level $X$. If the injurer has the opportunity to buy liability insurance, his utility level is defined as:

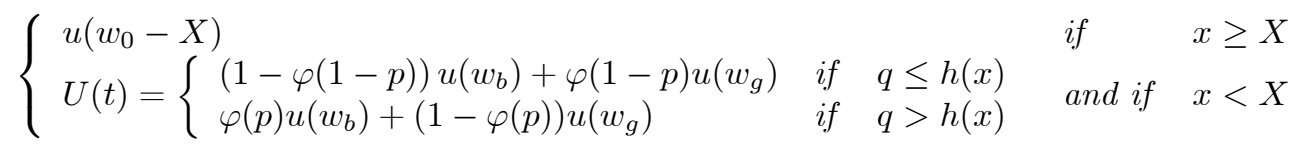

where $w_{b}, w_{g}$ have been defined previously. The result is straightforward. 
Proposition 15 Assume that liability coverage is offered in a private insurance market. Then, under the negligence rule with a standard of care $X$ :

i) The injurer complies with any standard of care $X \leq \hat{x}$ and buys no insurance if $\left.\zeta \in] 0, \frac{1-\varphi(1-p)}{p}-1\right]$.

ii) The injurer complies with a standard of care $X=x^{*}$ and buys no insurance if $\left.\zeta \in] 0, \frac{1-\varphi(1-p)}{p}-1\right]$ and: $x^{*}-x_{\zeta}<(1+\zeta) \operatorname{ph}\left(x_{\zeta}\right)$.

iii) The injurer complies with any standard of care $X \geq x^{*}$ and buys no insurance if $\zeta \in\left[\frac{\varphi(p)}{p}-1,0\right]$ and: $X-x_{\zeta}<(1+\zeta) \operatorname{ph}\left(x_{\zeta}\right)$.

iv) The injurer complies with any standard $X$ and buys no insurance if $\zeta>$ $\frac{1-\varphi(1-p)}{p}-1$ and: $u(w-X)>(1-\varphi(1-p)) u\left(w_{b}\right)+\varphi(1-p) u\left(w_{g}\right)$.

Proof. The injurer complies to $X$ if we have generally: $u\left(w_{0}-X\right)<U(t)$. The injurer needs insurance coverage only when he expects to be found liable. In this case, we are back to the strict liability rule.

Consider first the situation where $\left.\zeta \in] 0, \frac{1-\varphi(1-p)}{p}-1\right]$ which implies full insurance. i) Facing a standard $X \leq \hat{x}$, if the injurer does not comply, he chooses a level of care $x_{\zeta}<\hat{x}$. Since $u\left(w_{0}-X\right) \geq u\left(w_{0}-\hat{x}\right)>u\left(w_{0}-x_{\zeta}\right)>$ $u\left(w_{0}-x_{\zeta}-(1+\zeta) p h\left(x_{\zeta}\right)\right)$, the result i) follows.

ii) Facing a standard $X=x^{*}$, if the injurer does not comply, he chooses a level of care $x_{\zeta} \lessgtr x^{*}$. If $u\left(w_{0}-x^{*}\right)>u\left(w_{0}-x_{\zeta}-(1+\zeta) p h\left(x_{\zeta}\right)\right) \Longleftrightarrow x^{*}-x_{\zeta}<$ $(1+\zeta) p h\left(x_{\zeta}\right)$, the result ii) follows.

Consider the situation now where $\left.\zeta \in] 0, \frac{1-\varphi(1-p)}{p}-1\right]$ also associated to full insurance.

iii) If the standard is set at $X \geq x^{*}$, and if the insurer do not comply, he chooses $x_{\zeta} \leq \hat{x}$. Then, if $u\left(w_{0}-X\right)>u\left(w_{0}-x_{\zeta}-(1+\zeta) p h\left(x_{\zeta}\right)\right)$, the result iii) follows.

Proposition 15 shows that when insurance markets are imperfect, negligence may allow to implement different care levels, depending on the combination between a standard $X$ and a tariff of insurance $\zeta$. Case i) shows that the injurer may comply to a small standard of care when insurers charge not too high premia (such that the injurer has the opportunity to buy full coverage for liability insurance). Case ii) shows that the injurer may not comply to a standard set at the first best level of care, unless its cost is smaller than the expected cost associated to safety and a full insurance contract. Case iii) displays a situation where the injurer complies to a high standard of safety (larger than the fist best one), although liability insurance is subsidized; compliance occurs as far as the cost of this high standard is smaller than the expected cost associated to non compliance and full insurance. Finally case iv) means that when the injurer cannot obtain but incomplete (partial) liability insurance, he is likely to comply to any standard set as low as possible. 


\section{Conclusion}

The aim of the paper was to revisit the unilateral accident model, taking into account for the limited opportunities of risk spreading when aggregate losses exist in the specific cases of major industrial accidents. Typically, theses ones correspond to a situation of small probability/large (catastrophic) damages, for which it is well known that individuals display behavioral biases in the perception of the risk. As a result, it is well documented that insurance markets may experience serious failures. When insurance coverage is available, companies charge high levels of premium, and offer indemnity schedules which are characterized by both deductibles on small losses and caps and upper limits on large ones. Typically, when an insurance demand exist, it is heavily constrained and full insurance is not possible.

Two salient results have been obtained in such circumstances. First, we characterized the first best outcome of such an economy (assuming RDEU representation of preferences) both in terms of risk sharing and care level, and showed that the choice of the safety investment decision corresponds to a higher level of care than in a risk-free/risk-neutral economy. Second, we proved that in contrast to recent papers, the implementation of safety through tort law may at best allow to reach a second best outcome, even when markets insurance are introduced. Moreover, negligence does not always lead to a better situation than strict liability.

Our results show that not only pessimism is important for the analysis of the functioning of tort law, but the specific assumption regarding individual preferences and the specific definition of pessimism is important: in our framework, pessimism leads to results which are the opposite of Teitelbaum (2007)'s ones. Coming back to the general shape of the probability transformation function in graph 1 , it is obvious that our analysis may be extended to such a case, although additional but technical difficulties should occur. More specifically, depending on the intervalle to which baseline risk $p$ pertains, a richer comparative statics analysis should be obtained. However, note that our results are robust to the extent that $p$ is in the domain of small probabilities such as $p_{0}$ for which the probability distortion is still convex: this is because locally, the distortion is pessimistic and thus the subjective likelihood of accident will be larger than the probability of accident. In contrast, considering the domain of marger probabilities such as $p_{1}$ for which the probability distortion is now concave, it comes that locally, the distortion is optimistic and thus the subjective likelihood of accident will be smaller than the probability of accident, which may reverse some of our results. This is left for future researches.

A typical extension of our work is also to take into account for the heterogeneity in individuals' risk perceptions. Another line of research is the issue of the optimal mix of ex ante regulation and ex post liability for highly risky activities. 


\section{References}

Abdellaoui M. (2000), Parameter-free elicitation of utility and probability weighting functions, Management Sciences, 46, 1497-1512.

Abdellaoui M. and Munier B. (1997), Experimental Determination of Preferences under Risk : the Case of very Low Probability Radiation, Ciencia y Technelogia dos Materiais, 19, Lisboa, Portugal.

Arlen J. (1992a), Liability for physical injury when injurers as well as victims suffer losses, Journal of Law, Economics \& Organization, 8, 411-426.

Arlen J. (1992b), Should defendants' wealth matter?, Journal of Legal Studies, 21, 413-429.

Arrow K. (1964), Optimal insurance and generalized deductibles, Scandinavian Actuarial Journal, 1, 1-42.

Baron D. (1971), Demand uncertainty and imperfect competition, International Economic Review, 12, 196-208.

Bigus J. (2006), Tort liability and probability weighting function according to Prospect Theory, communication to the American Law $\&$ Economics Association Annual Meeting in 2006.

Borch J. (1962), Equilibrium in a reinsurance market, Econometrica, 30, 424-444.

Bouyssou D. and Vansnick J-C. (1990), Utilité Cardinale dans le certain et choix dans le risque, Revue Economique, 6, 979-1000.

Brown J. P. (1973), Toward an economic theory of liability, Journal of Legal Studies, 2, 323-349.

Calabresi G. (1970), The Cost of Accidents - A Legal and Economic Analysis, Yale University Press.

Carlier G., Dana R-A. and Sahidi N. (2003), Efficient insurance contracts under Epsilon-Contaminated Utilities, The Geneva Papers on Risk an Insurance Theory, 28, 59-71.

Chateauneuf A. and Cohen M. (1994), Risk-seeking with diminishing marginal utility in a non expected utility model, Journal of Risk and Uncertainty, 9, 77-91.

Chateauneuf A., R.-A. Dana and J.M. Tallon (2000), Optimal risk sharing rules and equilibria with Choquet-expected-utility, Journal of Mathematical Economics, 34, 191-214.

Chateauneuf A., Eichberger J. and Grant S. (2003), Choice under uncertainty with the best and worst in mind: neo-additive capacities, Cahier de la MSE 2003-01, CERMSEM-Université Paris 1-Panthéon-Sorbonne.

Chew S., E. Karni and Z. Safra (1987), Risk aversion in the theory of Expected Utility with Rank Dependent Preferences, Journal of Economic Theory, 42, 370-381.

Chew S. and Zilcha I. (1990), Invariance of the efficient sets when the Expected Utility hypothesis is relaxed, Journal of Economic Behavior and Organization, 13, 125-131.

Chiu W. (2000), On the propensity to self protect, The Journal of Risk and Insurance, 67, 555-578. 
Cohen M. (1995), Risk aversion concepts in expected - and non-expected utility models, The Geneva Papers on Risk and Insurance Theory, 20, 73-91.

Cooter R. (1986), Liability rules and risk sharing in environmental and resources policy: discussion, American Journal of Agricultural Economics, 68, 1276-1278.

Courtault J-M. and Gayant J-P. (1998), Local risk aversion in the rank dependent expected utility model: First order versus second order effects, Economics Letters, 59, 207-212.

Dari-Mattiacci G. (2005), Errors and the functioning of tort liability, Supreme Court Review, 13, 165-187.

Dari Mattiacci G. \& Franzoni L. (2010), Innovation under liability law, Mimeo.

Dari-Mattiacci G. and Langlais E. (2009), Social wealth and optimal care, Amsterdam Center for Law $\&$ Economics Working Paper No. 2008-05, Tinbergen Institute.

Deffains B. and Langlais E. (Eds) (2009), Analyse Economique du Droit Principes, Méthodes, Résultats, De Bøeck Université.

de Geest G. and Dari-Mattiacci G. (2005), Soft regulators, tough judges, Supreme Court Review, 15, 119-140.

Diamond P. (1974a), Single accident activity, 3, Journal of Legal Studies, 3, 107-164.

Diamond P. (1974b), Accident law and resource allocation, The Bell Journal of Economics and Management Science, 5, 366-405.

Drèze J. (1987), Essays on economic decisions under uncertainty, Cambridge University Press.

Dupuis A. and Langlais E. (1997), The basic analytics of insurance demand and the Rank-Dependent Expected Utility model, Finance - Revue de l'AFFI, 48, 47-76.

Eide E. (2005), Accident liability with Rank Dependent Expected Utility, Working Paper, Université d'Oslo.

Endres A. \& Bertram R. (2006), The development of care technology under liability law, International Review of Law and Economics, 26, 503-518.

Endres A. \& Friehe T. (2010), Too much R\&D although polluters underestimate environmental harm ?, Mimeo.

Etner J., Jeleva M. and Jouvet P-A. (2007), Risk perception, voluntary contributions and environmental quality, Research in Economics, 61, 130-139.

Fees E., Muehlheusser G. \& Wohschlegel A. (2009), Environmental liability under uncertain causation, European Journal of Law and Economics, 28, 133148 .

Graff Zivin J. and Small A. (2003), Risk sharing in Coasian contracts, Journal of Environmental Economics and Management, 45, 394-415.

Graff Zivin J., R. Just and D. Zilberman (2006), Risk aversion, liability rules and safety, International Review of Law and Economics, 25, 604-623.

Green J. (1976), On the optimal structure of liability laws, The Bell Journal of Economics and Management Science, 7, 553-574. 
Greenwood, P. and Ingene P. (1978), Uncertainty externalities, liability rules and resources allocation, American Economic Review, 68, 300-310.

Hansen R. and Thomas R. (1999), The efficiency of sharing liability for hazardous waste: effects of uncertainty over damages, International Review of Law and Economics, 19, 135-157.

Hogarth R. M. and Kunreuther H (1985), Ambiguity and insurance decisions, American Economic Review (AEA Papers and Proceedings), 75, 386-390.

Hogarth R. M. and Kunreuther H (1989), Risk, ambiguity, and insurance, Journal of Risk and Uncertainty, 2, 5-35.

Jacob J. (2010), Technical choice, liability and information acquisition in the presence of ambiguity about the risk of accident, Mimeo.

Jeleva M. and Rossignol S. (2009), Political decision of risk reduction: the role of trust, Public Choice.

Jullien B., B. Salanié and F. Salanié (1999), Should more risk-averse agents exert more effort?, The Geneva Papers on Risk and Insurance, 24, 19-28.

Kaplow L. and S. Shavell (1994), Why the legal system is less efficient than the income tax in redistributing income?, Journal of Legal Studies, 23, 667-681.

Kaplow L. and S. Shavell (2000), Should legal rules favor the poor? Clarifying the role of legal rules and the income tax in redistributing income, Journal of Legal Studies, 29, 821-835.

Khilstrom R. and Roth A. (1982), Risk aversion and the negotiation of insurance contracts, The Journal of Risk and Insurance, 49, 372-387.

Kunreuther H., Hogarth R. M., Meszaros J. (1993), Insurer ambiguity and market failure, Journal of Risk and Uncertainty, 7, 71-87.

Kunreuther H., Meszaros J., Hogarth R. M., Spranca, M. (1995), Ambiguity and underwriter decision processes, Journal of Economic Behavior and Organization, 26, 337-352.

Landes W. M. and R. A. Posner (1987), The economic structure of tort law, Cambridge, MA: Harvard University Press.

Landsberger M. and I. Meilijson (1994), Co-monotone allocations, BickelLehmann dispersion and the Arrow-Pratt measure of risk-aversion, Annals of Operations Research, 52, 97-106.

Lee K. (1998), Risk-aversion and self-insurance-cum-protection, Journal of Risk and Uncertainty, 17, 139-150.

Lee K. (2005), Wealth effects on self-insurance and self-protection against pecuniary and non-pecuniary losses, The Geneva Risk and Insurance Review, 30, 147-159.

Leland H. (1972), Theory of the firm facing random demand, American Economic Review, 62, 278-291.

Lichtenstein S, Slovic P., Fischhoff B., Layman M. and Combs B. (1978), Judged Frequency of Lethal Events, Journal of Experimental Psychology: Human Learning and Memory, 4, 551-578.

Machina M. (1987), Choice under uncertainty: Problems solved and unsolved, Journal of Economic Perspectives, 1, 121-154.

Magill M. and Quinzii M. (1996), Theory of Incomplete Markets (vol. 1), MIT Press. 
Mossin J. (1968), Aspect of rational insurance purchasing, Journal of Political Economy, 76, 553-568.

Miceli T. and K. Segerson (1995), Defining efficient care: the role of income distribution, Journal of Legal Studies, 24, 189-208.

Nell M. and A. Richter (2003), The design of liability rules for highly risky activities - Is strict liability superior when risk allocation matters?, International Review of Law and Econmics, 23, 31-47.

Nussim J. and Tabbach A. (2009), A revised model of unilateral accidents, International Review of Law and Econmics, 29, 169-177.

Pratt J. (1964), Risk aversion in the small and inthe large, Econometrica, 32, 122-136.

Posner R. (2003), Probability errors: some positive and normative implications for tort and contract law, Supreme Court Economic Review, 11, 125-141.

Raviv A. (1979), The design of optimal insurance policy, American Economic Review, 69, 84-96.

Roëll A. (1987), Risk aversion in Quiggin and Yaari's rank-order model of choice under uncertainty, The Economic Journal, 97, 143-159.

Salanié F. and Treich N. (2009), Regulation in Happyville, The Economic Journal, 119, 665-679.

Sandmo A. (1971), On the theory of the competitive firm under price uncertainty, American Economic Review, 61, 65-73.

Sarin R. and Wakker P. (2000), Cumulative dominance and probabilistic sophistication, Mathematical Social Sciences, 40, 191-196.

Segal U. and Spivak A. (1990), First order versus second order risk aversion, Journal of Economic Theory, 51, 111-125.

Segerson K. (1986), Risk sharing and the design of environmental policy, American Journal of Agricultural Economics, 68, 1261-1265.

Shavell S. (1981), A note on efficiency versus distributional equity in legal rulemaking: should distributional equity matter given optimal income taxes?, American Economic Review - Papers and Proceedings, 71, 414-418.

Shavell S. (1982), On liability and insurance, The Bell Journal of Economics, 13, 120-132.

Shavell S. (1986), The judgment proof problem, International Review of Law and Economics, 6, 45-58.

Shavell S. (1987), Economic Analysis of Accident Law, Cambridge, MA: Harvard University Press.

Stott H. (2006), Cumulative prospect theory's functional menagerie, Journal of Risk and Uncertainty, 32, 101-130.

Sweeney G. and T. Beard (1992), The comparative statics of self-protection, The Journal of Risk and Insurance, 59, 301-309.

Teitelbaum J. (2007), A unilateral accident model under ambiguity, Journal of Legal Studies, 36, p. 431-477.

Tversky A. and Wakker P. (1995), Risk attitudes and decision weights, Econometrica, 63, 1255-1280.

Viscusi K. (2001), Jurors, judges and the mistreatment of risk by the courts, Journal of Legal Studies, 30, 107-142. 
Viscusi W., Vernon V. and Harrington J. (2000), Economics of Regulation and Antitrust, chapitre 19: «The emergence of health, safety and environmental regulation », MIT Press.

Wakker P. (1994), Separating marginal utility and probabilistic risk aversion, Theory and Decision, 36, 1-44.

Wakker P. and Tversky A. (1993), An axiomatization of Cumulative Prospect Theory, Journal of Risk and Uncertainty, 7, 147-175.

Watabe A. (1999), The effect of liability-sharing rules in delegating hazardous activities, International Review of Law and Econmics, 19, 349-368.

Yaari M. (1987), The Dual Theory of choice under risk, Econometrica, 55, 95-116. 


\section{Appendix}

Assume a decision maker having preferences which satisfy the RDEU axiomatic; then, there exists two functions:

- a probability transformation $\varphi:[0,1] \times[0,1] \rightarrow[0,1]$ unique, continuous and increasing in $p$, with $\varphi(0)=0$ and $\varphi(1)=1$,

- and a utility index $u$, increasing (unique up to a affine transformation),

such that facing a risky prospect $X=\left(x_{1}, 1-p ; x_{2}, p\right)$, with $x_{1}<x_{2}$, then his satisfaction level is :

$$
\begin{aligned}
V(X) \equiv & \left(\varphi\left(\operatorname{Pr} o b\left(X \geq x_{1}\right)\right)-\varphi\left(\operatorname{Pr} o b\left(X>x_{1}\right)\right)\right) v\left(x_{1}\right) \\
& +\left(\varphi\left(\operatorname{Pr} o b\left(X \geq x_{2}\right)\right)-\varphi\left(\operatorname{Pr} o b\left(X>x_{2}\right)\right)\right) v\left(x_{2}\right) \\
\equiv & (1-\varphi(p)) v\left(x_{1}\right)+\varphi(p) v\left(x_{2}\right)
\end{aligned}
$$

It is well known that two different definitions for the concept of risk aversion, namely:

- risk aversion in the sense of Rothschild and Stiglitz - aversion to a meanpreserving spread of risk, which allows tocompare two risky situations, differing according to the second stochastic dominance order;

- risk aversion in the sense of Arrow and Pratt - prefering the certainty of the expected gamble to the gamble, we compare certainty to a risky outcome,

are both characterized by the concavity of the utility index in the Expected Utility model. In contrast, in the RDEU framework, risk aversion in the sense of Rothschild and Stiglitz is equivalent to $\varphi$ convex and $u$ concave (Chew and ali (1990)): this is a concept of strong aversion to risk (Cohen (1995)), that is aversion to marginal shifts in risk. In contrast, risk aversion in the sense of Arrow and Pratt does not necessarily require that $u$ be concave, as far as $\varphi$ is sufficiently convex (Chateauneuf and Cohen (1994)): this is a concept of weak risk aversion, or aversion to a global increase in risk.

In the literature, the convexity of $\varphi$ is also associated to a behavior termed probabilistic risk aversion (litteraly: aversion to probability mixtures) or strong pessimism (Roël (1987), Wakker (1994), Yaari (1987)).

The consequence of the convexity of $\varphi$ together with the conditions $\varphi(0)=$ 0 and $\varphi(1)=1$, is that $\varphi(q)<q$ for all $q \in[0,1]$. Thus, the way a risk averse decision maker evaluates the prospect $X$ in the RDEU model implies that $1-\varphi(p)>1-p$ : he over estimates the probability of the smaller gain $1-p$, and $\varphi(p)<p$, he under estimates the probability of the larger one $p$. 